Estudios Geológicos, 66(2)

julio-diciembre 2010, 255-284

ISSN: $0367-0449$

doi:10.3989/egeol.39778.055

\title{
Estado actual del conocimiento de los mamíferos fósiles de Chile
}

\section{Present knowledge on the fossil mammals record from Chile}

\author{
J. Canto', ${ }^{1,}$ J. Yáñez ${ }^{1,2}$, J. Rovira ${ }^{3}$
}

\begin{abstract}
RESUMEN
Se presenta una revisión de los mamíferos fósiles de Chile, de ambientes terrestres y acuáticos, conocidos hasta el año 2008; no se consideran aquellos registros de dudosa asignación o que no pudieron ser localizados. Los registros son agrupados en cuatro rangos temporales que se distribuyen a partir del Eoceno tardío-Oligoceno temprano hasta el Pleistoceno-reciente. Se evidencia que la mayor cantidad de registros fósiles se concentra en el lapso Mioceno inferior a Mioceno medio, llegando a $37(41,5 \%)$ géneros de un total de 77 y $54(49,5 \%)$ especies fósiles de un total de 89 . Se comprueba un aumento significativo de trabajos sobre paleontología en mamíferos fósiles en Chile entre 1981 y 2008.
\end{abstract}

Palabras clave: Paleontología, Mamíferos, Fósiles, Chile.

\section{ABSTRACT}

An updated revision is presented regarding fossil mammals of aquatic and terrestrial environments. This update includes up to year 2008. Those registrations of doubtful assignation or that couldn't be confirmed were not considered in this review. These new registrations are classified in four groups of time that extend from the Late Eocene-Early Oligocene to the Pleistocene-Recent. The evidence shows that the greatest quantity of fossils are concentrated from the Early Miocene to the Middle Miocene reaching $37(41.5 \%)$ genus of a total of 77 and $54(49.5 \%)$ fossil species of a total of 89 . It is observed a significant increase in works devoted to paleontology of mammal fossils in Chile between 1981-2008.

Key words: Paleontology, Mammals, Fossils, Chile.

\section{Introducción}

Los mamíferos representan uno de los últimos clados de vertebrados, en el que se observa el desarrollo de innovaciones anatómicas que los diferencian de otros grupos de vertebrados, permitiendo agruparlos en una clase propia, Mammalia. Las innovaciones más conspicuas están representadas por el desarrollo de una cubierta pilosa y la producción de leche destinada a la alimentación de las crías (Kardong, 1999). A nivel óseo existen varios elementos únicos que son propios de esta clase. El más notable es la presencia de un dentario, como pieza íntegra de la totalidad de la mandíbula, que articula mediante una unión craneomandibular que comprende el cóndilo dentario y la unión escamosa glenoidea. De acuerdo a Luo et al. (2002) la definición de mamífero se considera desde el ancestro inmediato a Sinocodon. El registro fósil para este grupo es conocido desde hace poco más de $200 \mathrm{mi}$ llones de años, durante el Triásico superior (Alférez, 1990), alcanzando su mayor expresión durante

\footnotetext{
1 Área Zoología, Museo Nacional de Historia Natural, Santiago, Chile. Casilla 787, Santiago, Chile.

Email: jcanto@paleontologica.org, jyanez@mnhn.cl

2 Paleontológica. Investigación, Educación, Conservación del patrimonio paleontológico. Área Proyectos. Santiago, Chile.

Email: secretaria@paleontologica.org

3 Comisión Nacional del Medio Ambiente (CONAMA), Santiago, Chile. Email: jrovira@ conama.cl
} 
el Terciario, momento que presenta la mayor diversificación, como lo testimonian los hallazgos fósiles (Simpson, 1985).

Actualmente, los mamíferos vivientes representan cerca de 5.000 especies, reunidas en aproximadamente 549 géneros distribuidos en todo el mundo con una amplia diversificación y extensión en variados ambientes, tanto terrestres como acuáticos (Eisenberg, 1981). Sin embargo, esta cantidad es mucho menor en términos de diversidad taxonómica al compararla numéricamente con ensambles presentes a lo largo del Cenozoico para los mamíferos terrestres en la región sudamericana, y para los cetáceos a nivel global (Simpson, 1985; Uehn \& Pyenson, 2007).

Del total de especies de mamíferos vivientes, Chile reúne 150 nativas agrupadas en nueve órdenes, 28 familias y 85 géneros (Muñoz \& Yáñez, 2000) que se establecen principalmente a partir de finales del Pleistoceno, salvo excepciones para algunos grupos, como los xenartros y cetáceos que son de mayor antigüedad.

Restos fósiles de mamíferos son conocidos en nuestro territorio de hace al menos 31,5 a 33 millones de años (Oligoceno temprano), procedentes de Chile Central (Región del Libertador Bernardo O'Higgins), descubiertos en dos áreas. Una en el valle del río Tinguiririca (Croft et al., 2003b) y la otra en el río Cachapoal (Hitz et al., 2006).

Estos nuevos descubrimientos han puesto de manifiesto que la existencia de los mamíferos es mucho más temprana para Chile de lo que se conocía previamente.

En términos históricos el conocimiento de la paleomastozoología del país data desde el siglo XIX, gracias al trabajo de Claudio Gay en 1847 , quien realizó una primera descripción de Mastodon andium en su obra «Historia física y política de Chile». Sin embargo, el trabajo sobre fósiles de mamíferos ha sido bastante precario, obedeciendo más bien a esfuerzos acotados de investigadores nacionales y extranjeros. Entre 1855 y 1980 (125 años) se publicaron solamente 44 trabajos con un total de 429 páginas (Frassinetti 1982). Gracias a la recopilación realizada por Tamayo \& Frassinetti (1980), se dispone de un primer catálogo completo de las faunas de mamíferos actuales y fósiles de Chile. Con posterioridad, los últimos 27 años (1980 a 2008) han evidenciado un trabajo sostenible sobre la paleomastozoología nacional (Canto \& Frassinetti, 2008; Canto et al., en prensa $a y b)$.

\section{Evolución y expansión de los mamíferos en Sudamérica}

Después de la separación de Sudamérica de Gondwana (hace unos 136 millones de años) se inició la diversificación de los mamíferos (Paula Couto, 1979; Reig, 1981); sin embargo, el momento más significativo se produjo hace unos 65 millones de años, tiempo en que éstos comienzan a exhibir una amplia variedad y también un aumento en su abundancia, lo que quedó reflejado en los conjuntos de extraordinarias formas, tanto terrestres como acuáticas, que se desarrollaron a lo largo del Terciario y que han sido descubiertas en el registro fósil en toda Sudamérica en los últimos 200 años.

La diversificación que experimentó este grupo en Sudamérica guarda relación con los eventos tectónicos acaecidos a finales del Cretácico o comienzos del Terciario, lo que propició una región que se transformó, por un largo período, en un continenteisla casi en su totalidad, salvo en la sección austral, a nivel de la Antártica (Simpson, 1985). Esta situación tuvo un marcado impacto en la evolución de distintos linajes de mamíferos únicos y muy distintos a otras especies del resto del planeta.

Los primeros restos de mamíferos en Sudamérica se remontan a unos 130 millones de años (Pascual \& Ortiz-Jaureguizar, 2007). El primer conjunto de faunas de mamíferos que habitaron Sudamérica es conocido como Paleohorofauna y abarca desde el Cretácico superior al Eoceno (Reig, 1981). Se caracterizó por la existencia de grandes grupos: litopternos, piroterios, astrapoterios, notoungulados, xenartros y marsupiales, de ellos los cuatro primeros linajes están completamente extintos, en tanto que los últimos han sobrevivido hasta la actualidad, pero representados con una menor diversidad.

Posteriormente a este proceso, en el Oligoceno y particularmente durante el Mioceno hasta el Plioceno, tiene lugar una importante inmigración de mamíferos procedentes de Norteamérica y África dando lugar a un ensamble conocido como Cenohorofauna, caracterizado por presentar un conjunto de faunas mamíferas mixtas, es decir, algunas extintas y otras que han llegado hasta la actualidad (Reig, 1981).

El último evento orogénico de importancia ocurrió hace unos tres millones de años, con el levantamiento del istmo de Panamá, dando inicio al Gran Intercambio Americano, GABI (Great American Biotic Interchange) (Webb, 1976; Marshall, 1982; Webb, 2006), entre Norte y Sudamérica, y que habría permitido un intercambio de faunas desde y hacia América del 
Norte. Tradicionalmente la expansión de faunas entre ambas Américas se planteaba como un argumento central en la extinción de varios linajes de mamíferos sudamericanos a causa de una supuesta «inferioridad» de éstos. Sin embargo, estudios recientes cuestionan y plantean que las extinciones de algunos linajes estarían relacionados con el tamaño corporal, es decir, que animales más grandes presentarían mayores probabilidades de extinguirse que los de menor talla (Lessa \& Fariña, 1996; Cione et al., 2003).

Los fósiles que se han descubierto a lo largo de los años en América del Sur son los testimonios que han permitido documentar los cambios en la composición de los diferentes elencos de mamíferos (Marshall et al., 1983; Pascual et al., 1996). En el caso particular de Chile, el conocimiento de las faunas paleomastozoológicas ha aumentado de forma significativa a partir de los últimos años (Moreno et al., 1994; Flynn \& Wyss, 1998; Casamiquela, 1999), posibilitando reconfigurar nuestra comprensión de la biogeografía y evolución de los mamíferos en Chile desde sus primeras evidencias en el Oligoceno y su desarrollo evolutivo hasta el presente.

La literatura existente revela la presencia de distintos elencos faunísticos que habitaron y evolucionaron en Chile entre el Paleógeno y el Holoceno y que están estrechamente relacionados con las constantes transformaciones del paisaje, producto de los diferentes fenómenos geomorfológicos que se han sucedido a finales del Cretácico e inicios del Cenozoico a nivel sudamericano, condición que afectó a las faunas de mamíferos tanto marinas como continentales. Más aún, Pascual et al. (1996) señalan que los cambios registrados en las faunas terrestres de Sudamérica se correlacionan con las temperaturas y la variación de los niveles de los océanos.

Todo esto resulta evidente al apreciar el recambio constante de los linajes de mamíferos continentales registrados para Chile, mostrando fluctuaciones en el número de géneros, así como la aparición y extinción de familias.

Para el caso de los mamíferos acuáticos existen registros documentados desde el siglo XIX en adelante (Philippi, 1887; Gigoux 1899, 1913; DonosoBarros, 1975). La historia de este grupo en Chile es conocida a partir del Mioceno superior, extendiéndose hasta el presente algunas familias de los órdenes Carnívora y Cete (= Cetacea), mientras que otros (Sirenia) y formas acuáticas de Xenarthra se extinguieron (Sielfeld, 1983; Canto et al., 1991, 1994; Canto et al., 2002 a, b; Staig et al., 2004; Bianucci et al., 2006; Canto et al., 2008).

\section{Materiales y métodos}

Se efectuó una recopilación de la bibliografía disponible en revistas científicas nacionales y extranjeras sobre mamíferos fósiles. A partir de estas fuentes se realizó una revisión detallada de las faunas de mamíferos fósiles presentes en Chile.

En el caso de aquellas especies que fueron reasignadas, se indica el cambio de taxón. Para las referencias con restos fósiles dudosos, que no se localizó el material fósil respectivo (por ejemplo Cetacea: Squalodon), fueron descartadas de la revisión, dado que no pueden ser corroboradas. Con la finalidad de facilitar la consulta de información se indica la fuente bibliográfica principal para cada taxón determinado. Aquellos registros que se presentan sólo a nivel familiar y/o genérico obedece a que están fundados sobre la base de material fósil poco diagnóstico.

Los taxones fueron separados en cuatro rangos de tiempo geológico (1. Eoceno tardío? - Oligoceno temprano; 2. Mioceno inferior - Mioceno medio; 3. Mioceno medio tardío - Plioceno temprano; 4. Pleistoceno-reciente), permitiendo de esta forma relacionarlos en una escala de tiempo, de manera de apreciar su aparición en el registro fósil de Chile. Los períodos geológicos están basados en la escala proporcionada por Gradstein \& Ogg (2004).

$\mathrm{El}$ análisis de cada conjunto de mamíferos fósiles se inicia desde el Oligoceno, ya que es, de momento, el registro más antiguo para el país y se extiende hasta el Reciente que se considera hasta los últimos 10.000 años AP, en base al registro de mamíferos fósiles (Casamiquela, 1999).

También se utilizaron las edades proporcionadas por Ortiz-Jaureguizar y Cladera (2006). No se consideró la utilización de las SALMAs (South American Land-Mammals Ages) como unidades cronológicas para todos los mamíferos, debido a que éstas no abarcan los mamíferos acuáticos, por lo tanto se menciona puntualmente el SALMA sólo para aquellos grupos de mamíferos en que la designación es relevante en el análisis general. Debe señalarse además que el SALMA no es una unidad formal y es considerada de esa forma en este trabajo, situación ya mencionada por Cione \& Tonni (1995).

Para la discusión de la distribución de los fósiles a nivel territorial se consideró más adecuado organizar el país en cinco zonas geográficas: 1) norte (desde Arica a Paposo); 2) norte chico (Taltal a Los Vilos); 3) centro (La Ligua a Parral); 4) sur (Chillán a Chaitén), y 5) austral (Melinka a Tierra del Fuego) (fig. 1). Se considera que esta organización es más 


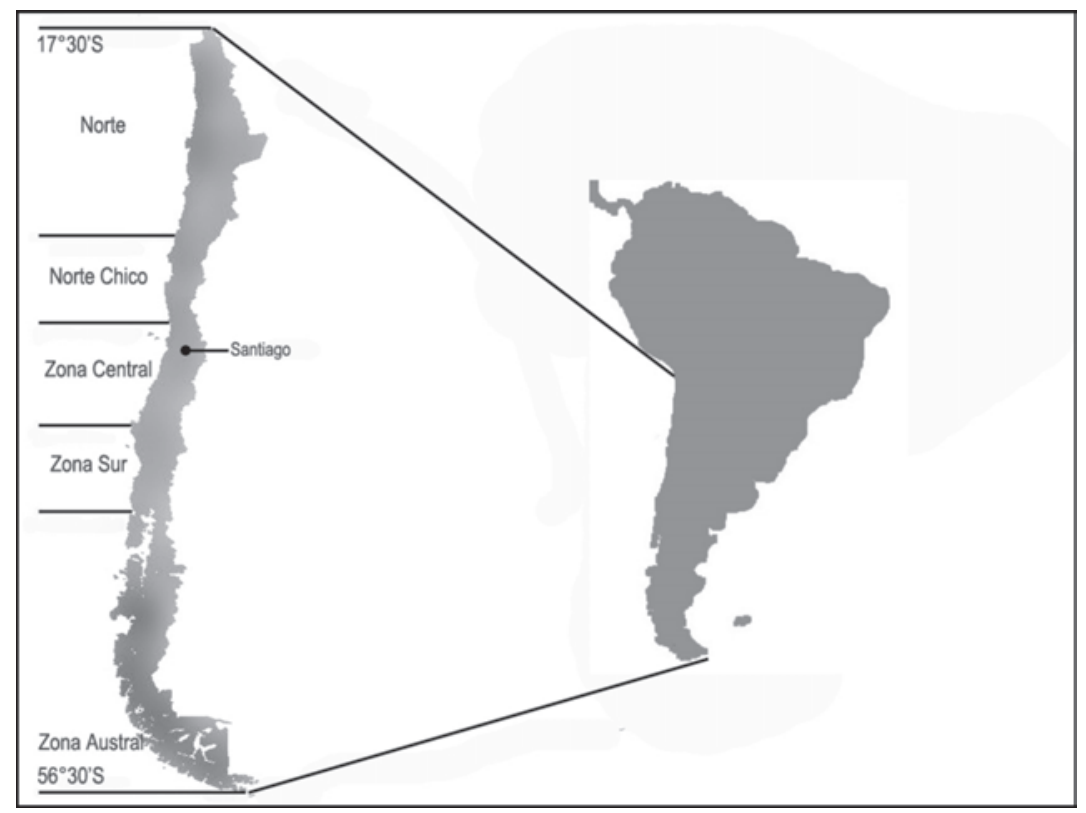

Fig. 1.-Mapa de Chile que presenta la organización espacial de las cinco zonas geográficas en que se distribuyen los mamíferos fósiles en Chile.

estable en el tiempo para efectos del tratamiento de los registros, ya que las regiones administrativas pueden presentar modificaciones en sus límites, lo que comprometería cualquier análisis que aborde las distribuciones de mamíferos fósiles.

Para la nomenclatura taxonómica de los mamíferos se utilizó el trabajo desarrollado por McKenna \& Bell (1997), razón por la que hay modificaciones en el nivel de varios taxones con respecto a los utilizados en otros trabajos (Canto 2007; Canto et al., 2002a, 2007), especialmente en mamíferos marinos, que se basaron en la nomenclatura propuesta por Barnes et al. (1985).

Para la nomenclatura de las series dentarias, las piezas superiores (maxilares) se señalan con un número con formato superíndice y para las piezas mandibulares un número en formato subíndice. Se antecede con el signo † cuando el taxón está extinto.

Hemos considerado que cuando los descriptores de la especie superen los tres autores, utilizaremos sólo el primer autor seguido de la expresión et al.

\section{Resultados}

En los últimos 27 años (1981-2008) ha existido un notable aumento en el número de trabajos sobre mamíferos fósiles de Chile, registrándose un total de 59 trabajos en el período. Esto tiene una especial significancia al compararlo con los antecedentes proporcionados por Frassinetti (1982), quien señala que entre los años 1855 y 1980 se publicaron 44 trabajos, arrojando un promedio de 0,34 publicaciones por año; lo que resalta los 2,18 trabajos por año en el período 1981-2008, y que refleja un incremento de 6,4 veces en los últimos 27 años. Es necesario aclarar que la mayoría de estas publicaciones se enmarcan en la descripción de nuevos restos fósiles, y/o ampliación en sus rangos de extensión en el territorio de Chile, así como primeros registros de una categoría taxonómica, particularmente a nivel de género, e inclusive como familia.

\section{Distribución de faunas por rango de edad}

¿Eoceno Tardío?-Oligoceno temprano (37-33 millones de años) (tabla 1)

A este período corresponde el registro fósil más antiguo de mamíferos conocidos en Chile. Está representado por faunas de mamíferos agrupados en varias familias extintas: Archaeohyracidae, Interatheriidae, Groeberiidae, Polydolopidae, Chinchillidae, Isotemnidae, Homalodontotheriidae, Notohippidae y el Suborden Phyllophaga. Las características únicas de este ensamble de faunas han permitido el establecimiento de una nueva edad biocronológica, 
Tabla 1.-¿Eoceno tardío?-Oligoceno temprano (37-33 millones de años)

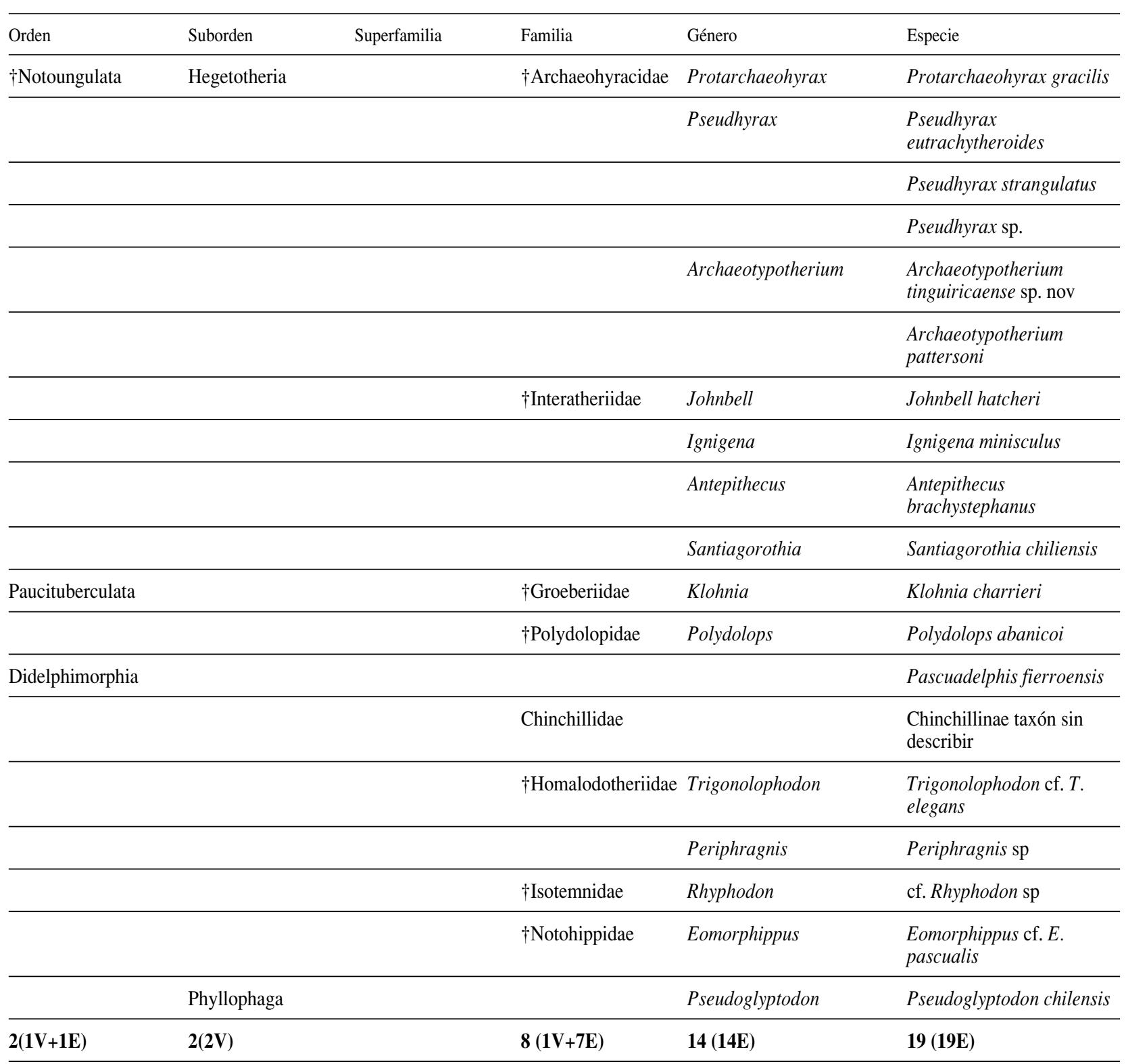

SALMA, denominada «Tinguiririense» (Flynn et al., 2003), nombre procedente del área geográfica de los descubrimientos de los restos fósiles, valle de Tinguiririca. Este yacimiento abarca además el sector alto del río Cachapoal.

Los materiales fósiles para este período son:

Orden $\uparrow$ Notoungulata Roth, 1903

Suborden Hegetotheria Simpson, 1945

Familia Archaeohyracidae Ameghino, 1897

Los representantes de esta familia se caracterizan por ser mamíferos muy primitivos. Presentan un cráneo aplastado pro- visto de nasales largos. Poseen dentición hipsodonta, pero con raíces y serie dental completa, sin diastema.

Protarchaeohyrax gracilis Reguero et al., 2003

Materiales y procedencia: Los restos corresponden a dientes aislados y fragmentos mandibulares. Zona centro, cercanías de las Termas del Flaco y a unos dos kilómetros al noroeste del río Tinguiririca.

Protarchaeohyrax intermedium Reguero et al., 2003

Materiales y procedencia: Fragmentos de pares de dentario con restos dentarios. Zona centro, cercanías de las Termas del Flaco, al sur del río Tinguiririca. 


\section{Pseudhyrax eutrachytheroides Ameghino, 1901}

Materiales y procedencia: Fragmentos maxilares y mandibulares con conservación parcial de los restos dentarios. Zona centro. La localidad es señalada como «desconocida», aunque se menciona su presencia en el SALMA Tinguiririense (Croft et al., 2003b; Flynn et al., 2003).

\section{Pseudhyrax strangulatus (Ameghino, 1901)}

Materiales y procedencia: Un fragmento mandibular derecho con restos parciales del $\mathrm{M}_{2}-\mathrm{M}_{3}$. Zona centro. La localidad es señalada como «desconocida» por Flynn et al. (2003), aunque menciona su presencia en el SALMA Tinguiririense (Croft et al., 2003b).

\section{Pseudhyrax sp.}

Materiales y procedencia: Un fragmento mandibular izquierdo con restos parciales del $\mathrm{M}_{1}-\mathrm{M}_{3}$. Zona centro. Se menciona su pertenencia al SALMA Tinguiririense (Croft et al., 2003b).

\section{Archaeotypotherium tinguiricaense Croft et al., 2003b}

Materiales y procedencia: Un fragmento de rostro con conservación de $\mathrm{C}^{1}-\mathrm{M}^{2}$ izquierdo que corresponde al holotipo. Se reportan además otros materiales representados por fragmentos dentarios, mandibulares, maxilares y cráneo. Zona centro, aproximadamente un kilómetro al norte del portezuelo El Fierro, al sur del río Tinguiririca, noroeste del cerro Alto del Padre, y sobre tres kilómetros al sur de Termas del Flaco.

\section{Archaeotypotherium pattersoni Croft et al., 2003b}

Materiales y procedencia: Maxilar derecho con parte de dientes, $\mathrm{P}^{2}-\mathrm{M}^{3}$, de la porción labial. También se conoce la rama mandibular derecha con el $\mathrm{P}_{2}-\mathrm{M}_{3}$. Zona centro, a un kilómetro al norte del portezuelo El Fierro, al sur del río Tinguiririca, noroeste del cerro Alto del Padre, y sobre tres kilómetros al sur de Termas del Flaco.

Suborden Typotheria Zittel, 1892

Familia Interatheriidae Ameghino, 1897

Se caracterizan por presentar un cráneo entre ancho y alto, notablemente acortado. Dentición hipsodonta, completa o muy poco reducida. Incisivos radiculados. En formas como Miocochilius hay reducción de los dedos del tipo paraxónico (Alcalá \& Morales, 1995).

\section{Johnbell hatcheri Hitz et al., 2006}

Materiales y procedencia: Fragmentos de maxilar izquierdo y mandíbula con porción sinfisiaria, además restos de un paladar y mandíbulas parcialmente preparadas. Zona centro, valle del río Tinguiririca, Formación Abanico (Flynn et al., 2003).

\section{Ignigena minisculus Hitz et al., 2006}

Materiales y procedencia: Fragmento maxilar con parte del zigomático y un fragmento mandibular con restos dentarios. Zona central, localidad Tapado, situada a unos tres kilómetros del río Tinguiririca, Formación Abanico.

\section{Antepithecus brachystephanus Hitz et al., 2006}

Materiales y procedencia: Un cráneo parcial con parte del paladar relacionado con algunos restos dentarios y una porción del zigomático derecho. Zona centro, valle del río Azufre, al norte del río Tinguiririca, Formación Abanico.

\section{Santiagorothia chiliensis Hitz et al., 2000}

Materiales y procedencia: Los restos corresponden a fragmentos de un cráneo con mandíbula y dentición casi completa. Otros materiales referidos están representados por cráneos, mandíbulas, piezas dentarias. Zona centro, localidad del portezuelo El Fierro, valle del río Tinguiririca, Formación Abanico.

\section{Familia $†$ Homalodotheriidae Gregory, 1910}

Grupo de notoungulados (Toxodonta) de gran tamaño. Presentan miembros muy modificados, terminados en garras en vez de pezuñas (Alcalá \& Morales, 1995).

Trigonolophodon cf. T. elegans Roth, 1903

Materiales y procedencia: Un resto mandibular. Zona centro, valle del Tinguiririca (Wyss et al., 1994; Flynn et al., 2003), Región del Libertador Bernardo O'Higgins.

\section{Periphragnis sp.}

Materiales y procedencia: Varios molares. Zona centro, área del valle del Tinguiririca (Wyss et al., 1994; Flynn et al., 2003).

\section{Familia †Isotemnidae Ameghino, 1897}

Se considera un grupo basal de toxodontes. Cráneo de grandes proporciones. Por lo general presentan dentición completa. Sus incisivos son espatulados, caninos grandes y molares braquiodontos. Los premolares superiores son triangulares. Los molares superiores presentan el ectolofo unido a un protolofo oblicuo y metalofo más transversal y corto. Los premolares de la parte inferior se transforman gradualmente en molariformes con talónido corto. Los molares inferiores presentan un trigónido corto. Herbívoros u omnívoros (Alcalá \& Morales, 1995).

\section{cf. Rhyphodon sp.}

Materiales y procedencia: Fragmentos mandibulares y restos dentarios. Zona centro, valle de Tinguiririca, Región del Libertador Bernardo O'Higgins (Wyss et al., 1994; Flynn et al., 2003).

\section{Familia $†$ Notohippidae Ameghino, 1895}

Comprende a representantes toxodontos del Paleógeno. Son animales de talla moderada con dentición completa. Poseen molares lofodontos e hipsodontos (Alcalá \& Morales, 1995).

\section{Eomorphippus cf. E. pascualis (Simpson, 1967)}

Materiales y procedencia: Un fragmento de la maxila que ha conservado $\mathrm{P}^{2}$, la mitad de $\mathrm{M}^{1}$ y $\mathrm{M}^{3}$ emergiendo. Zona centro, valle del Tinguiririca, Región del Libertador Bernardo O’Higgins (Wyss et al., 1994; Flynn et al., 2003).

\section{Suborden Toxodontia Owen, 1853 \\ Familia †Homalodotheriidae Gregory, 1910}

Grupo de notoungulados (Toxodonta) de gran tamaño. Presentan miembros muy modificados, terminados en garras en vez de pezuñas (Alcalá \& Morales, 1995). 


\section{Trigonolophodon cf. T. elegans Roth, 1903}

Materiales y procedencia: Un resto mandibular. Zona centro, valle del Tinguiririca (Wyss et al., 1994; Flynn et al., 2003), Región del Libertador Bernardo O’Higgins.

\section{Periphragnis sp.}

Materiales y procedencia: Varios molares. Zona centro, área del valle del Tinguiririca (Wyss et al., 1994; Flynn et al., 2003).

Orden Paucituberculata Ameghino, 1894

Familia Groeberiidae Patterson, 1952

Esta familia de marsupiales presenta un solo género, con adaptaciones de tipo roedor en su dentición. Los dientes inferiores presentan fórmula $\mathrm{I}_{1} \mathrm{C}_{0} \mathrm{P}_{0} \mathrm{M}_{4}$. Los incisivos son del tipo hipselodonto, muy largo y comprimidos lateralmente con un mínimo esmalte en su cara anterior, separados de las otras piezas dentarias por un diastema. Los molariformes $\left(\mathrm{M}_{1} \circ \mathrm{P}_{3}\right)$ de tamaño normal. Los molariformes sublinguales no multicuspidados, con el paracónido antero-externo. La mandíbula se presenta muy corta y alta y fundida en la sínfisis. El proceso coronoide es fuerte y con una amplia fosa mesentérica (Paula Couto, 1979).

\section{Klohnia charrieri Flynn \& Wyss, 1999}

Materiales y procedencia: Una mandíbula derecha con parte de las piezas dentarias $\mathrm{P}_{3}-\mathrm{M}_{3}$. Otros materiales referidos son piezas dentarias y fragmentos de premaxilar y también maxilares. Zona centro, valle del río Tinguiririca, Termas del Flaco, Formación Abanico.

Familia Polydolopidae Ameghino, 1897

Son marsupiales con especialización sectorial de los $\mathrm{P}^{2}$ y $\mathrm{P}^{3} \mathrm{y}$ el $\mathrm{P}_{3}$. El $\mathrm{M}_{1}$ es trigónido. Los incisivos son pequeños. El canino inferior está bien desarrollado. Cráneo en que los arcos zigomáticos y el rostro se presentan anchos. Paladar perforado. Mandíbula con sínfisis sin fusionar y proceso angular fuerte (Soria, 1990).

\section{Polydolops abanicoi Flynn \& Wyss, 1999}

Materiales y procedencia: Los restos fósiles corresponden a una rama mandibular izquierda con el canino. Zona centro, dos kilómetros al noroeste de Termas del Flaco, Región del Libertador Bernardo O’Higgins. Formación Abanico.

\section{Orden Didelphimorphia Gill, 1872,}

Para efectos de este trabajo se consideró que los caracteres presentados por Paula Couto (1979) a nivel de Superfamilia, representan de mejor manera a este orden, en el entendido que la taxonomía de este rango presenta varias definiciones (Soria, 1990). Son marsupiales de pequeño tamaño con fórmula dentaria $\mathrm{I}_{4-3}^{5}, \mathrm{C}_{1}{ }_{1}, \mathrm{P}^{3}{ }_{3}$ $\mathrm{M}_{4}^{4}$. Los incisivos son reducidos, los caninos fuertes, premolares simples y cortantes y un tanto obtusos, y los molares superiores con cíngulo externo elevado a nivel de la superficie triturante de la corona, provistos de dentículos marginales bien definidos.

Trígono completo, hipocono y ectocono ausentes. Molares inferiores con trígono completo, generalmente más alto que el talónido.

\section{$\dagger$ Pascuadelphis fierroensis Flynn \& Wyss, 1999}

Materiales y procedencia: Una rama mandibular derecha con fragmentos dentarios. Zona centro, a dos kilómetros al noroeste de Termas del Flaco, al norte del río Tinguiririca, Región del Libertador Bernardo O'Higgins.

\section{Familia Chinchillidae Bennet, 1833}

Son roedores caviomorfos herbívoros estrictos. Presentan molares simples, con uno o dos sinclinales, de crecimiento continuo. Para el SALMA Tinguiririense es mencionada una forma atribuida como:

\section{Chinchillinae taxón sin describir (Flynn et al., 2002a)}

Materiales y procedencia: Piezas dentarias, así como restos craneales. Zona norte, quebrada Chucal, Región de Arica y Parinacota, Formación Chucal.

Suborden Phyllophaga Owen, 1842

$\dagger$ Pseudoglyptodon chilensis McKenna et al., 2006

Materiales y procedencia: Un cráneo y una mandíbula dañada con la dentición aparentemente completa. Zona centro, valle del Tinguiririca, a unos siete kilómetros de la frontera con Argentina, Región del Libertador Bernardo O’Higgins.

Las diferentes especies documentadas para este período se asentaron en ambientes caracterizados por estaciones secas y hábitats abiertos, similares a una sabana boscosa y/o praderas. Los mamíferos en general son de tamaños corporales pequeños y medianos. Las masas corporales de acuerdo a Lessa \& Fariña (1996) pueden agruparse en tres categorías: Small (pequeño) de menos de $1 \mathrm{~kg}$, Medium (mediano) entre 1 a $100 \mathrm{~kg}$ y Large (grande) más de $100 \mathrm{~kg}$. Una de las características de esta comunidad es la dominancia de herbívoros de corona alta. Su evolución se asoció a un cambio climático.

\section{Mioceno inferior - Mioceno medio (18 a 15 millones de años) (tabla 2)}

La situación paleoambiental en este lapso para el territorio chileno comienza a experimentar una serie de cambios geológicos y climáticos que afectarán los ensambles de fauna de mamíferos (Charrier et al., 2007).

\section{Los materiales fósiles para este período son:}

Superorden Microbiotheria Ameghino, 1889 Familia Microbiotheriidae Ameghino, 1887

Corresponde a marsupiales de talla pequeña. Poseen un cráneo grande y rostro corto. La región interorbital es ancha. Premaxilares muy alargados. Los nasales se presentan extendidos hacia atrás. No se presenta proceso paraoccipital. Proceso escamoso pequeño y corto. Región auditiva especializada, con una enorme bula timpánica, en relación a otros marsupiales, en la que se observa que los dos tercios posteriores están formados por una nueva osificación denominada entotimpánico. El tercio anterior se forma por el proceso timpánico del aliesfenoides. El ectotimpánico no forma parte de la bula timpánica, sino que queda englobado dentro de ella. Sínfisis mandibular no fusionada y el 
Tabla 2.-Mioceno inferior-Mioceno medio (20-10 millones de años)

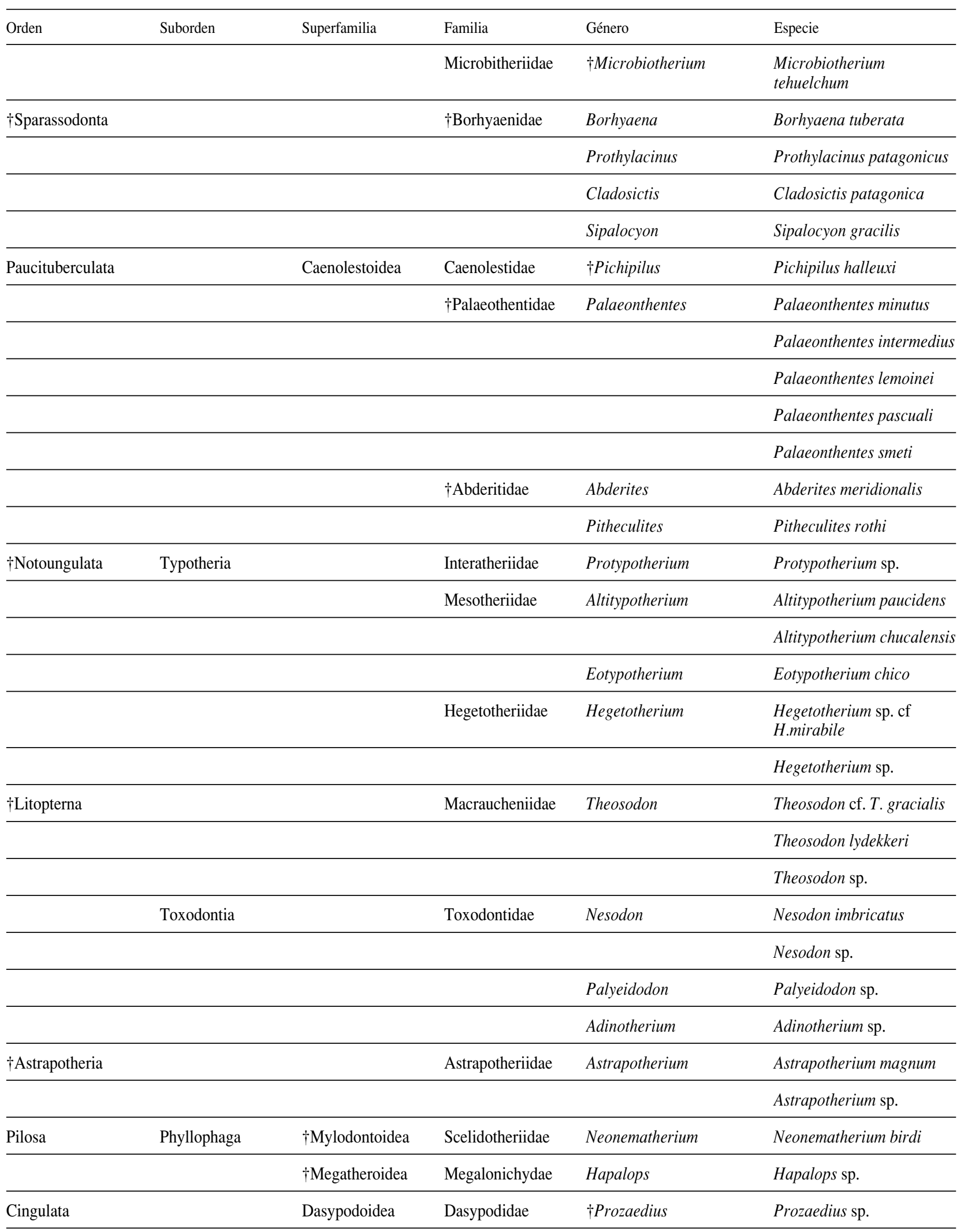


Tabla 2.-Mioceno inferior-Mioceno medio (20-10 millones de años) (continuación)

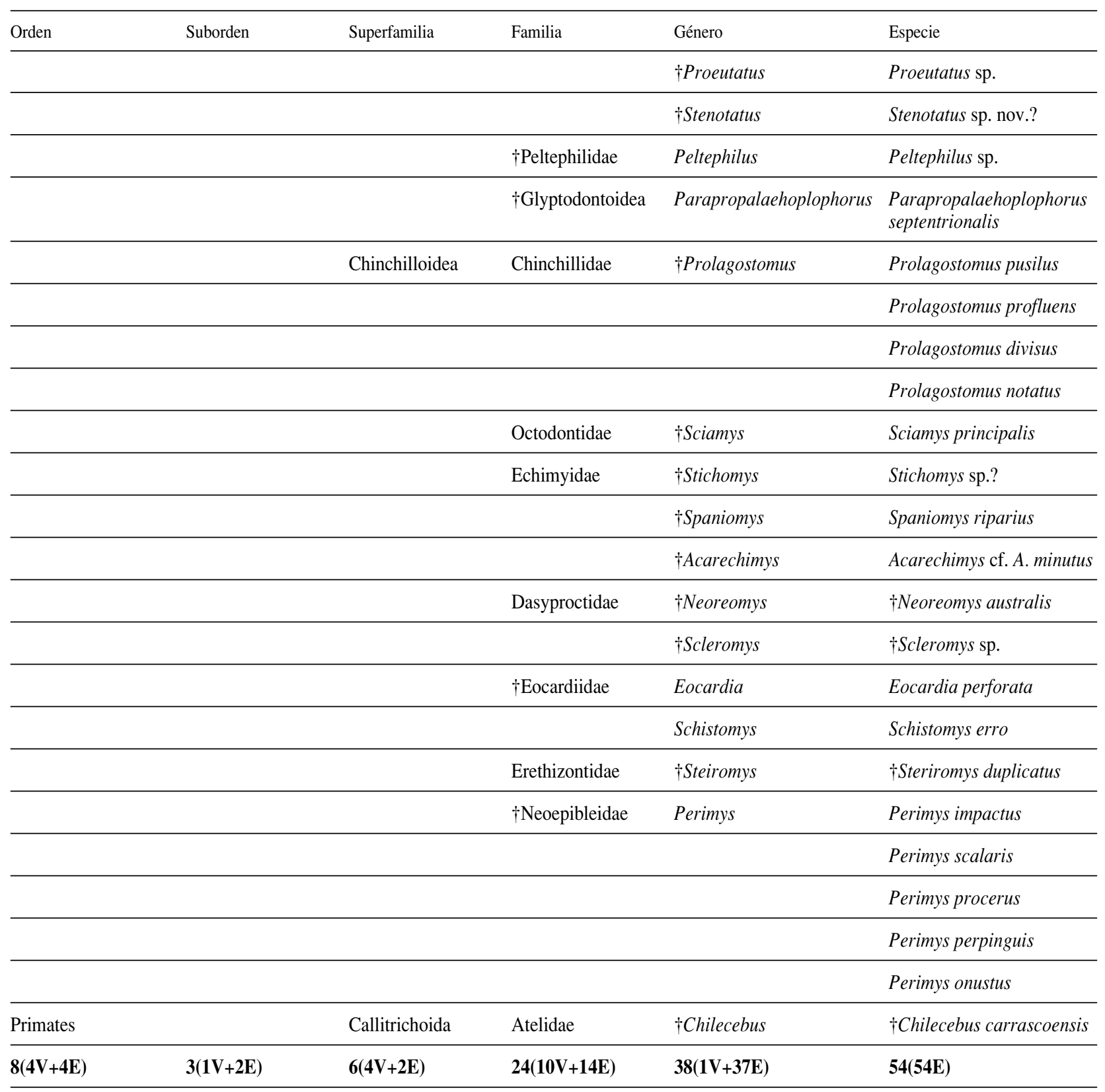

proceso angular es sobresaliente y con marcada inflexión. Fórmula dentaria $\mathrm{I}_{4}^{5} \mathrm{C}_{1}^{1} \mathrm{P}_{3}^{3} \mathrm{M}_{4}^{4}$. Incisivos anchos y espatulados. Último molar más pequeño que el primero. Molares braquiodontos, en los cuales los inferiores poseen un trigónido con cúspides bajas. Metacónido situado lingualmente con respecto al protocónido. Talónido más ancho que el trigónido (Soria, 1990).

\section{$†$ Microbiotherium tehuelchum Ameghino, 1887}

Materiales y procedencia: Parte de un dentario izquierdo con $\mathrm{M}_{3-5}$. Zona austral, Alto Río Cisnes, Región de Aisén (Marshall, 1990).
Orden $†$ Sparassodonta Ameghino, 1894

Subfamilia Hathliacyninae Ameghino, 1894

Marsupiales de talla pequeña a media. Presentan un cráneo dolicocéfalo con una bula timpánica grande y osificada compuesta por el aliesfenoides que conforma los dos tercios anteriores y la pars mastoidea del periótico compone el tercio posterior. Fórmula dentaria $\mathrm{I}_{3}^{4} \mathrm{C}_{1}^{1} \mathrm{P}_{3}^{3} \mathrm{M}_{4}^{4}$. Incisivos sublinguales. Caninos moderadamente desarrollados. En los molares inferiores se observa un incremento en el tamaño del $\mathrm{M}_{1}$ a $\mathbf{M}_{4}$. Falanges ungueales sin fisurar, puntiagudas y comprimidas lateralmente (Soria, 1990). 


\section{Familia Borhyaenidae Ameghino, 1894}

Presenta cráneo dolicocéfalo a braquicéfalo. Rostro robusto con grandes nasales que se expanden posteriormente. Contacto nasal y lacrimal distinguible, sin orificio postorbital. Tanto el proceso basiesfenoides y el basioccipital incrementa su anchura posteriormente, sin quilla apreciable en ninguno de los dos. En la pars petrosa del periótico hay ausencia del proceso timpánico. El hipogloso es grande con presencia de orificios postescamoso y postglenoideo. Fórmula dentaria $\mathrm{I}^{3-4}{ }_{3-4} \mathrm{C}^{1}{ }_{1} \mathrm{P}_{3}^{3} \mathrm{M}_{4}^{4}$. Los caninos se presentan bien desarrollados. Se observa que las raíces están cerradas en adultos. Los molares presentan un aumento de tamaño desde $\mathrm{M}_{1}^{1}{ }_{1} \mathrm{M}_{4}^{3}$, observándose en los superiores un protocono variable en tamaño. También es posible encontrar un talónido de tamaño variable (Soria, 1990).

\section{Borhyaena tuberata Ameghino, 1887}

Materiales y procedencia: Gran parte del protocónido y el talonoide completo del $\mathrm{M}_{3}$ izquierdo. Zona austral, Alto Río Cisnes, Región de Aisén (Marshall, 1990).

\section{Prothylacinus patagonicus Ameghino, 1891}

Materiales y procedencia: Parte del dentario derecho con la raíz de $\mathrm{M}_{2}$, la base de $\mathrm{M}_{3}$ y las raíces de $\mathrm{M}_{4}$. Zona austral, Alto Río Cisnes, Región de Aisén (Marshall, 1990).

\section{Subfamilia $†$ Hathliacynidae Ameghino, 1894}

Los representantes de esta familia son de pequeño tamaño, con cráneo dolicocéfalo, con una bula timpánica grande y osificada (alisfenoides conforma los dos tercios anteriores y la pars mastoidea corresponde al tercio posterior). Los forámenes son ovales. El lacerum posterior y la carótida posterior, grandes (Soria, 1990).

\section{Sipalocyon gracilis Ameghino, 1887}

Materiales y procedencia: Parte de la maxila derecha con $\mathrm{M}^{2-3}$ gastados y la raíz anterior de $\mathrm{M}^{4}$. Zona austral, Alto Río Cisnes, Región de Aisén (Marshall, 1990).

\section{Cladosictis patagonica Ameghino, 1887}

Materiales y procedencia: $\mathrm{M}_{4}$ aislado y que ha perdido la base posterior del talónido; paracónido y borde anterior del protocónido del $\mathrm{M}_{5}$ izquierdo; paracónido y borde más anterior del protocónido del $\mathrm{M}_{3} \mathrm{o} \mathrm{M}_{4}$ derecho; parte anterior del dentario izquierdo con la sínfisis completa, alvéolos $\mathrm{I}^{1-3}$, base rota del C y raíces de $\mathrm{P}_{1}$. Zona austral, Alto Río Cisnes, Región de Aisén (Marshall, 1990).

Orden $†$ Paucituberculata Ameghino, 1894

Familia Caenolestidae Trouessart, 1898

Grupo endémico de Sudamérica que se caracteriza por poseer mandíbulas con sínfisis no fusionada y el proceso angular prominente con una fuerte desviación. Fórmula dentaria $\mathrm{I}^{3-4}{ }_{2-4}$ $\mathrm{C}_{1}^{1} \mathrm{P}_{2-3}^{3} \mathrm{M}_{4}^{4}$. Para el $\mathrm{I}_{1}$ se evidencia que es ancho y de orientación casi horizontal (Soria, 1990).

\section{Pichipilus halleuxi Marshall, 1990}

Materiales y procedencia: Parte del dentario derecho con la mitad posterior del $\mathrm{P}_{3}$ y el $\mathrm{M}_{2}$ completo. Zona austral, Alto Río Cisnes, Región de Aisén (Marshall, 1990).

\section{Familia Palaeothentidae Sinclair, 1906}

Presentan un cráneo alargado. Los arcos zigomáticos se presentan muy desarrollados. Fórmula dental $\mathrm{I}_{2}^{3} \mathrm{C}_{1}{ }_{1} \mathrm{P}^{3}{ }_{2-3} \mathrm{M}_{4}^{4}$. En el $\mathrm{I}_{1}$ la situación es de orientación casi horizontal y es seguido de tres o cuatro dientes vestigiales $\left(\mathrm{I}_{2} \mathrm{C} \mathrm{P}_{1-2}\right)$. El $\mathrm{P}_{3}$ presenta una morfología del tipo cortante. Trigónido de $\mathrm{M}_{1}$ alargado, con un metacónido desarrollado. $\mathrm{M}_{2-3}$ son braquiodontos, sin lofos. Se observa que los $\mathrm{P}^{1-2}$ están muy reducidos, siendo el $\mathrm{P}^{3}$ muy grande y ensanchado posteriormente. A nivel del borde labial de $\mathrm{M}^{1-2}$ se presenta cortante (Soria, 1990).

\section{Palaeonthentes minutus Ameghino, 1887}

Materiales y procedencia: Parte derecha del dentario con conservación de $\mathrm{M}_{2-3}$; parte del dentario derecho con $\mathrm{P}_{3}$ completo; $\mathrm{M}^{2}$ izquierdo aislado; talónido izquierdo del $\mathrm{M}_{2}$. Zona austral, Alto Río Cisnes, Región de Aisén (Marshall, 1990).

\section{Palaeonthentes intermedius Ameghino, 1887}

Materiales y procedencia: Parte derecha del dentario con $\mathrm{M}_{2-3}$ completo; sección izquierda del dentario con raíces de $\mathrm{P}_{3}$, alvéolo de $\mathrm{M}_{2}$ y $\mathrm{M}_{3}$ completo. Zona austral, Alto Río Cisnes, Región de Aisén (Marshall, 1990).

\section{Palaeonthentes lemoinei Ameghino, 1887}

Materiales y procedencia: Parte del dentario derecho con $\mathrm{P}_{3}$ y $\mathrm{M}_{3-4}$ completos y los alvéolos de $\mathrm{P}_{2}, \mathrm{M}_{2}$ y $\mathrm{M}_{5}$. También parte del dentario izquierdo con el $\mathrm{M}_{3}$ completo y el alvéolo $\mathrm{M}_{4}$. Zona austral, Alto Río Cisnes, Región de Aisén (Marshall, 1990).

\section{Palaeonthentes pascuali Bown \& Fleagle, 1993}

Materiales y procedencia: Restos dentarios, especialmente molares. Zona austral, Pampa Castillo, Región de Aisén (Flynn et al., 2002b).

\section{Palaeonthentes smeti Flynn et al., 2002b}

Materiales y procedencia: Fragmento maxilar. Zona austral, Pampa Castillo, Región de Aisén.

\section{Familia Abderitidae Ameghino, 1889}

Este grupo se caracteriza por presentar un gran $\mathrm{I}_{1}$, que es ancho y procumbente (de orientación casi horizontal). Los $\mathrm{I}_{2} \mathrm{C}$ $\mathrm{P}_{1-2}$ son vestigiales y separados entre sí. El $\mathrm{M}_{1}$ carece de metacónido, mientras que el protocónido y el paracónido forman una lámina cortante y estriada, que se eleva con respecto al resto de la serie dental (Soria, 1990).

\section{Abderites meridionalis Ameghino, 1887}

Materiales y procedencia: $\mathrm{M}^{2}$ aislado y con pérdida de su raíz anterior; también un $\mathrm{M}^{2}$ aislado y con pérdida de su raíz anterior; $\mathrm{M}^{2}$ izquierdo aislado; $\mathrm{M}^{2}$ derecho aislado; $\mathrm{M}^{2}$ derecho aislado; parte de la maxila izquierda con el $\mathrm{M}^{2-4}$ gastado; parte del dentario derecho con $\mathrm{M}_{3}$ y los alvéolos de $\mathrm{M}_{4-5}$; parte del dentario derecho con $\mathrm{M}_{3}$ completo; $\mathrm{M}_{2}$ izquierdo aislado; $\mathrm{M}_{3}$ derecho aislado; $\mathrm{M}_{3}$ izquierdo aislado; $\mathrm{M}_{2}$ derecho aislado. Dentario izquierdo casi completo con $\mathrm{M}_{2-3}$ y los alvéolos $\mathrm{M}_{4-5}$; parte del dentario derecho con el talónido de $\mathrm{M}_{2}, \mathrm{M}_{3-4}$ gastados y alvéolo $\mathrm{M}_{5}$; trigónido de $\mathrm{M}_{2}$ izquierdo; gran parte del $\mathrm{I}_{1}$ izquierdo; parte basal del $\mathrm{I}_{1}$ derecho; parte derecha del dentario con base posterior de la raíz de $\mathrm{M}_{2}, \mathrm{M}_{3-4}$ completo y alvéolo 
$\mathrm{M}_{5}$; parte anterior del dentario derecho con la base de $\mathrm{I}_{1}$ seguido por cuatro pequeños alvéolos. Zona austral, Alto Río Cisnes, Región de Aisén (Marshall, 1990).

Pitheculites rothi Ameghino, 1902

Materiales y procedencia: Fragmento del dentario izquierdo con $\mathrm{M}_{3-4}$ completos y el alvéolo de $\mathrm{M}_{5}$. Zona austral, Alto Río Cisnes, Región de Aisén (Marshall, 1990).

Orden $†$ Notoungulata Roth, 1903

Suborden Typotheria Zittel, 1892

Familia Interatheriidae Ameghino, 1897

Protypotherium sp.

Materiales y procedencia: Restos mandibulares y dentición superior. Zona austral, Pampa Castillo, Región de Aisén (Flynn et al., 2002b)

\section{Familia $†$ Mesotheriidae Alston, 1876}

Son mamíferos pertenecientes al Orden Notoungulata, Suborden Typotheria. Poseen un cráneo muy especializado, en el que se observa un arco zigomático muy fuerte. La dentición es del tipo hipsodonta con reducción de los incisivos.

Los anteriores carentes de raíz. Los caninos y premolares anteriores se presentan reducidos. Los molares superiores son alargados (Alcalá \& Morales, 1995).

Altitypotherium paucidens Croft et al., 2004

Materiales y procedencia: Un rostro parcial con $\mathrm{I}^{1}$ izquierdo, $\mathrm{P}^{4}-\mathrm{M}^{3}$ izquierdo y $\mathrm{P}^{4}-\mathrm{M}^{1}$ derecho. Otros materiales están representados por fragmentos dentarios y restos mandibulares. Zona norte, Región de Arica y Parinacota, Formación Chucal (Charrier et al., 2005).

\section{Altitypotherium chucalensis Croft et al., 2004}

Materiales y procedencia: Un cráneo parcial sin los incisivos superiores y la mandíbula, parte de $\mathrm{P}^{3}$ derecho y $\mathrm{P}^{3-4}$ izquierdo y restos de los incisivos inferiores. Otros materiales están representados por piezas dentarias, fragmentos de mandíbulas, restos craneales, vértebras y partes del esqueleto axial. Zona norte del país, Región de Arica y Parinacota, Formación Chucal (Charrier et al., 2002).

\section{Eotypotherium chico Croft et al., 2004}

Materiales y procedencia: Los restos corresponden a parte de la maxila y el zigomático derecho. Otros restos estan representados por parte de maxilas, mandíbulas y piezas dentarias. Zona norte, Región de Arica y Parinacota, Formación Chucal (Charrier et al., 2002).

\section{Familia †Hegetotheriidae Ameghino, 1894}

Este grupo presenta un cráneo con un arco zigomático fuerte. La bula timpánica se divide en dos cavidades. Los incisivos superiores centrales son grandes. Premolares anteriores de forma cilíndrica (Alcalá \& Morales, 1995).

\section{Hegetotherium sp. cf. H. mirabile}

Materiales y procedencia: Restos maxilares, mandibulares, piezas dentarias y huesos del esqueleto axial. Zona norte del país, Región de Arica y Parinacota, Formación Chucal (Charrier et al., 2002).

\section{Hegetotherium sp.}

Materiales y procedencia: Restos craneales. Zona austral, Pampa Castillo, Región de Aisén (Flynn et al., 2002b).

Orden $†$ Litopterna Ameghino, 1889

Familia Macraucheniidae Gervais, 1855

Son litopternos tridáctilos. Sus extremidades son parecidas a las de los camellos. Presentan un cráneo, por lo general, bajo y alargado, cuya característica principal es el retraso progresivo de las aberturas nasales, que pueden llegar a desplazarse hasta la parte superior del cráneo. Poseen dentición braquiodonta, que es completa en formas más primitivas. En aquellas más modernas se observa reducción (Paula Couto, 1979).

†Subfamilia Cramaucheniinae Ameghino, 1902

Theosodon cf. T. gracialis

Materiales y procedencia: Piezas dentarias. Zona austral, Pampa Castillo, Región de Aisén (Flynn et al., 2002b).

\section{Theosodon lydekkeri Ameghino, 1887 (incluye a T. lallemanti)}

Materiales y procedencia: Dos dentarios: uno izquierdo con $\mathrm{M}_{1}, \mathrm{M}_{2}$ y $\mathrm{M}_{3}$ completos y el otro corresponde a la parte anterior del dentario derecho con el canino y $\mathrm{P}_{1}, \mathrm{P}_{2}, \mathrm{P}_{3}$ y $\mathrm{P}_{4}$. Zona austral, Puerto Natales, Estancia Consuelo (depositados en la Colección Colegio Salesiano «Monseñor José Fagnano»), Región de Magallanes (Marshall \& Salinas, 1989-1990).

\section{Theosodon sp.}

Materiales y procedencia: Piezas dentarias. Zona austral, Río Frías/Cisnes, Región de Aisén (Flynn et al., 2002b).

Suborden $†$ Toxodontia Owen, 1853

Familia Toxodontidae Owen, 1845

Los representantes de este grupo corresponden a toxodontes de talla robusta, con un cráneo corto, masivo y alto. Los miembros son cortos y los pies son tridáctilos. Dentición completa, los incisivos $\mathrm{I}^{1} \mathrm{e} \mathrm{I}^{3}$ presentan crecimiento continuo, y se han modificado en incisivos muy desarrollados unos, y molariformes del tipo hipsodonto otros (Alcalá \& Morales, 1995).

\section{Nesodon imbricatus Owen, 1846}

Materiales y procedencia: Un cráneo parcial con su lado derecho roto, otros restos de cráneos, piezas dentarias aisladas, fragmentos de mandíbula y restos del esqueleto axial. Zona norte, cercanías de la quebrada Chucal, Región Arica y Parinacota (Croft et al., 2004).

Nesodon sp.

Materiales y procedencia: Restos dentarios. Zona austral, Cerro Castillo, Región de Aisén (Flynn et al., 2002b).

\section{Palyeidodon (?) sp.}

Materiales y procedencia: Un fragmento mandibular con tres molares. Zona norte, Región Arica y Parinacota, Formación Chucal (Bond \& García 2002). 


\section{Adinotherium sp.}

Materiales y procedencia: Sólo se menciona el registro sin detalles de los materiales. Zona austral, Pampa Castillo, Región de Aisén (Flynn et al., 2002b).

Orden †Astrapotheria Lydekker, 1894

Familia Astrapotheriidae Ameghino, 1887

Los representantes de esta familia son de talla mediana. Presentan incisivos lobulados. Los molares superiores son cuadrangulares con un gran hipocono. Cresta sagital corta. Los elementos de la región auditiva expuesto ventralmente, evidenciándose que la bula timpánica es normal, sin sinus epitimpánico (Paula Couto, 1979; Alcalá \& Morales, 1995).

\section{Astrapotherium mangun Owen, 1893}

Materiales y procedencia: Un fragmento de la maxila izquierda con la conservación de las raíces de los premolares $\mathrm{P}^{3}$ y $\mathrm{P}^{4}$, y $\operatorname{los} \mathrm{M}^{1}, \mathrm{M}^{2}$ y $\mathrm{M}^{3}$. Zona austral, Alto Río Baguales, Última Esperanza, Región de Magallanes (Marshall \& Salinas, 1989-1990).

\section{Astrapotherium sp.}

Materiales y procedencia: Fragmentos dentarios. Zona austral, Pampa Castillo, Región de Aisén (Flynn et al., 2002b).

\section{Magnorden Xenarthra Cope 1889, nuevo rango McKenna y Bell 1997 \\ Orden Pilosa Flower, 1883 \\ Suborden Phyllophaga Owen, 1842 \\ Superfamilia $†$ Mylodontoidea Gill, 1872 \\ Familia Scelidotheriidae Ameghino 1889}

Presenta un cráneo estrecho y alargado. Las series dentarias son continuas y paralelas. En las extremidades posteriores el calcáneo tiene una conformación particular muy similar al género Ocnupus (Megalonychidae) (Meléndez, 1990).

\section{Neonematherium birdi Simpson, 1941}

Materiales y procedencia: Un cráneo casi completo. Zona austral, Cañadón La Leona, Laguna Blanca, Región de Magallanes. Formación Palomares.

Superfamilia $†$ Megatheroidea Gray, 1821

Tribu Nothrotheriini Ameghino, 1920,

nuevo rango McKenna \& Bell 1997

Hapalops sp.

Materiales y procedencia: Osteodermos y fragmentos menores. Zona austral, Cerro Castillo, Región de Aisén (Flynn et al., 2002b).

Orden Cingulata Illiger, 1811

Superfamilia Dasypodoidea Gray 1821

Familia Dasypodidae Gray, 1821

Reúne a los verdaderos armadillos, que presentan un número variable de osteodermos (bandas) transversales móviles. Se dividen en tres secciones: anterior, media y posterior. La anterior y la posterior corresponden a los escudos escapulares y pélvicos respectivamente. Se presenta además un escudo cefálico que cubre la parte superior de la cabeza. Sus miembros locomotores son cortos y fuertes, con dedos robustos y provistos de uñas curvadas. Dentición con 8 a 10 dientes indiferenciados (Paula Couto, 1979).

\section{Prozaedyus sp.}

Materiales y procedencia: Osteodermos y fragmentos de caparazón. Zona austral, Pampa Castillo, Región de Aisén (Flynn et al., 2002b).

\section{Proeutatus sp.}

Materiales y procedencia: Osteodermos y fragmentos de caparazón. Zona austral, Pampa Castillo, Región de Aisén (Flynn et al., 2002b).

\section{Stenotatus sp. nov.? Croft et al., 2007}

Materiales y procedencia: Conjuntos de osteodermos articulados y/o aislados; parte de un rostro, piezas dentarias, húmero derecho proximal, tibia izquierda distal, tres falanges asociadas, carpo izquierdo articulado. Zona norte, Región de Arica y Parinacota, Formación Chucal (Charrier et al., 2005).

\section{Familia Peltephilidae Ameghino, 1894}

Son armadillos con un cráneo totalmente diferente. Rostro corto y alargado, bóveda craniana abultada, provista de una cresta sagital. Grandes cóndilos occipitales situados bajo la línea alveolar. En la región nasal es ancha y aplastada, con la presencia de excrecencias análogas a cuernos. El paladar es más amplio lateralmente en su región media, por lo que las series dentarias superiores forman un arco alargado. Los dientes en forma de una serie arqueada continua en número que fluctúa entre 6-7/6-7. Transversalmente se presentan subtriangulares. Presentan desgaste oblicuo de afuera hacia adentro en las piezas superiores y viceversa en las inferiores (Paula Couto, 1979; Meléndez, 1990).

\section{Peltephilus sp.}

Materiales y procedencia: Osteodermos. Zona norte, cercanías de la quebrada Chucal, Región de Arica y Parinacota, Formación Chucal (Flynn et al., 2002a; Croft. et al., 2006).

\section{Superfamilia Glyptodontoidea Gray, 1869 \\ Parapropalaehoplophorus septentrionalis Croft et al., 2007}

Materiales y procedencia: Un esqueleto parcial, que incluye la rama mandibular izquierda, porción lateral izquierda del caparazón, porción antero-lateral derecha del caparazón, fémur izquierdo casi completo, fémur derecho parcial y articulación, también parcial, del tarso incluyendo unos restos de posiblemente la fíbula, el astrágalo y el calcáneo. También se han conservado algunos chevrones. Además se presenta una porción de la tibiofíbula izquierda, osteodermos. Zona norte, Región de Arica y Parinacota, Formación Chucal.

Parvorden Caviida Bryant \& McKenna, 1995

Superfamilia Chinchilloidea Bennett, 1833

Familia Chinchillidae Bennett, 1833

Este grupo posee molares de crecimiento continuo, bi a trilaminado. Se presenta desgaste en una pequeña área próxima a la base de la corona, de forma tal que se pierde rápidamente. Bulas timpánicas grandes. La mandíbula presenta una cresta masetérica lateral poco desarrollada y una apófisis coronoide débil. (Paula Couto, 1979). 


\section{Prolagostomus pusilus Ameghino, 1887}

Materiales y procedencia: Sólo se menciona el registro sin detalles de los materiales. Zona austral, Pampa Castillo, Región de Aisén (Flynn et al., 2002b).

\section{Prolagostomus profluens Ameghino, 1887}

Materiales y procedencia: Sólo se menciona el registro sin detalles de los materiales. Zona austral, Pampa Castillo, Región de Aisén (Flynn et al., 2002b).

\section{Prolagostomus divisus Ameghino, 1887}

Materiales y procedencia: Sólo se menciona el registro sin detalles de los materiales. Zona austral, Pampa Castillo, Región de Aisén (Flynn et al., 2002b).

Prolagostomus notatus Ameghino, 1887

Materiales y procedencia: Sólo se menciona el registro sin detalles de los materiales. Zona austral, Pampa Castillo, Región de Aisén (Flynn et al., 2002b).

Suborden Hystricognatha Woods, 1976

Familia Octodontidae Waterhouse, 1839

Dientes de corona baja a alta. Presentan molares de crecimiento continuo. La morfología oclusal es simplificada. Superficie masticatoria en forma de ocho (Paula Couto, 1979)

\section{Sciamys principalis Ameghino, 1887}

Materiales y procedencia: Sólo se menciona el registro sin detalles de los materiales. Zona austral, Pampa Castillo, Región de Aisén (Flynn et al., 2002b).

\section{Familia Echimydae Gray, 1825}

Presentan molares provistos de una foseta anterior y posterior más profundas, crestas (lofos) transversales más oblicuos con una marcada tendencia a la reducción y la pérdida del metalofido. $\mathrm{P}^{4-4}$ ausentes, excepto en géneros más primitivos, permaneciendo la dentición de leche correspondiente con la dentición definitiva. Dientes molariformes braquiodontos radiculados. Esta familia es reconocida desde el Oligoceno hasta el Reciente en América del Sur (Paula Couto, 1979).

Subfamilia †Adelphomyinae Patterson \& Pascual, 1968 Stichomys sp.?

Materiales y procedencia: Sólo se menciona el registro sin detalles de los materiales. Zona austral, Pampa Castillo, Región de Aisén (Flynn et al., 2002b).

Spaniomys riparius Ameghino, 1887

Materiales y procedencia: Restos dentarios, mandibulares y fragmentos de cráneo. Zona austral, Pampa Castillo, Región de Aisén (Flynn et al., 2002b).

Subfamilia Heteropsomyinae Anthony, 1917

$\uparrow$ Acarechimys cf. A.minutus Patterson, 1965

Materiales y procedencia: Restos dentarios, mandibulares y fragmentos de cráneo. Zona austral, Pampa Castillo, Región de Aisén (Flynn et al., 2002b).
Familia Agoutidae Gray, 1821

Los representantes poseen fórmula dental $\mathrm{I}_{1}^{1}, \mathrm{C}_{0}^{0}, \mathrm{P}_{1}^{1}, \mathrm{M}_{3}^{3}$. Arco zigomático masivo y característicamente esculpido (Redford \& Einsenberg, 1992).

Subfamilia Dasyproctinae Gray 1825

$\uparrow$ Neoreomys australis Ameghino, 1887

Materiales y procedencia: Restos dentarios, mandibulares y fragmentos de cráneo. Zona austral, Pampa Castillo, Región de Aisén (Flynn et al., 2002b).

\section{$\dagger$ Scleromys sp.}

Materiales y procedencia: Restos dentarios, mandibulares y fragmentos de cráneo. Zona austral, Pampa Castillo, Región de Aisén (Flynn et al., 2002b).

\section{Familia †Eocardiidae Ameghino, 1894}

Los representantes de esta familia poseen dientes hipsodontes, radiculados. Molariformes con corona medianamente alta. Los molariformes superiores presentan tres surcos externos delgados, los que con el desgaste se simplifican quedando divididos en dos prismas por un profundo surco intermedio. Se extienden desde el Oligoceno hasta el Mioceno inferior (Paula Couto, 1979).

\section{Eocardia perforata Ameghino, 1887}

Materiales y procedencia: Restos dentarios, mandibulares y fragmentos de cráneo. Zona austral, Pampa Castillo, Región de Aisén (Flynn et al., 2002b).

\section{Schistomys erro Ameghino, 1887}

Materiales y procedencia: Restos dentarios, mandibulares y fragmentos de cráneo. Zona austral, Pampa Castillo, Región de Aisén (Flynn et al., 2002b).

\section{Familia Erethizontidae Bonaparte, 1845}

Presentan dientes molariformes (premolares y molares) radiculados. Las bulas timpánicas son prominentes. Sus extremidades están fuertemente modificadas para la vida arborícola. Se extienden desde el Oligoceno hasta el Reciente (Paula Couto, 1979).

\section{$†$ Steriromys duplicatus Flynn et al., 2002b}

Materiales y procedencia: Restos dentarios, mandibulares y fragmentos de cráneo. Zona austral, Pampa Castillo, Región de Aisén.

Familia †Neoepibleidae Kraglievich, 1926

Presentan dientes compuestos por siete a ocho lofos transversales formados por una lámina continua de esmalte doblada repetidamente en forma de zigzag paralelo intercalado por cemento (Paula Couto, 1979).

\section{Perimys impactus Ameghino, 1887}

Materiales y procedencia: Restos dentarios, mandibulares y fragmentos de cráneo. Zona austral, Pampa Castillo, Región de Aisén (Flynn et al., 2002b). 
Perimys scalaris Ameghino, 1887

Materiales y procedencia: Restos dentarios, mandibulares y fragmentos de cráneo. Zona austral, Pampa Castillo, Región de Aisén (Flynn et al., 2002b).

Perimys procerus Ameghino, 1887

Materiales y procedencia: Restos dentarios, mandibulares y fragmentos de cráneo. Zona austral, Pampa Castillo, Región de Aisén (Flynn et al., 2002b).

Perimys perpinguis Ameghino, 1887

Materiales y procedencia: Restos dentarios, mandibulares y fragmentos de cráneo. Zona austral, Pampa Castillo, Región de Aisén (Flynn et al., 2002b).

\section{Perimys onustus Ameghino, 1887}

Materiales y procedencia: Restos dentarios, mandibulares y fragmentos de cráneo. Zona austral, Pampa Castillo, Región de Aisén (Flynn et al., 2002b).

Orden Primates Linnaeus, 1758

Suborden Euprimates Hoffstetter, 1978, nuevo rango McKenna y Bell, 1997

Superfamilia Callitrichoida Gray, 1821

Familia Atelidae Gray, 1825

Corresponde a platirrinos de talla, en general, mediana, cuya fórmula dentaria es $\mathrm{I}_{2}^{2} \mathrm{C}_{1}^{1} \mathrm{P}_{3}{ }_{3} \mathrm{M}_{3}^{3}$. Se extienden desde el Oligoceno hasta el Reciente (Paula Couto, 1979).

†Chilecebus carrascoensis Flynn et al., 1995

Materiales y procedencia: Un cráneo con deformación en el que se han conservado piezas dentarias. Zona central, Termas del Flaco, cercanías del río Las Leñas, Región del Libertador Bernardo O’Higgins, Formación Abanico.

\section{Mioceno tardío-Plioceno temprano (15 a 5 millones de años) (tabla 3)}

En este período de tiempo se evidencia un conjunto de transgresiones que afectó la línea de costa en varios puntos del territorio, posibilitando el desarrollo de nuevos ambientes y el surgimiento de especies asociadas a ellos (Marquardt et al., 2000; Charrier et al., 2007). De particular importancia es la aparición en el registro fósil de Chile de grupos mamíferos acuáticos (Canto, 2007; Canto et al., 2008).

Orden $\uparrow$ Notoungulata Roth, 1903

Suborden Typotheria Zittel, 1892

Familia Mesotheriidae Alston, 1876

Caraguatypotherium munozi Flynn et al., 2005

Materiales y procedencia: Un cráneo completo, vértebras cervicales, húmero articulado con el radio y la ulna y partes de la mano derecha e izquierda. Zona norte, Caragua, Región de Arica y Parinacota, Formación Huaylas.

Familia Hegetotheriidae Ameghino, 1894

cf. Hegetotherium torresi

Materiales y procedencia: Restos mandibulares y dientes. Zona norte, Quebrada Chucal, Región de Arica y Parinacota, Formación Chucal (Flynn et al., 2002a).

Magnaorden Xenarthra Cope, 1889, nuevo rango McKenna \& Bell, 1997

Orden Pilosa Flower, 1833

Suborden Phyllophaga Owen, 1842

Infraorden Megatheria McKenna \& Bell 1997

La definición más reciente para este taxón indica que corresponde al ancestro más reciente de Megatherioidea y Bradypodoidea y todos sus descendientes.

Superfamilia Megatherioidea Gray, 1821

Tribu Nothrotheriini Ameghino, 1920, nuevo rango McKenna y Bell, 1997

Thalassocnus $\mathrm{sp}$.

Materiales y procedencia: Fragmento de rama mandibular derecha en la que se han conservado tres piezas dentarias. Zona norte chico, Caldera, Región de Atacama, Formación Bahía Inglesa (Canto et al., 2008).

\section{Orden Uranotheria McKenna \& Bell, 1997}

Considera al más reciente ancestro común de Hyracoidea, Embrithopoda y Tethytheria y todos sus descendientes.

Suborden Tethytheria McKenna, 1975

Infraorden Sirenia Illiger, 1881,

nuevo rango McKenna \& Bell, 1997

Familia Dugongidae Gray, 1821

Dentición placentaria completa. Ausencia de dientes funcionales. Rostro comúnmente alargado con una flexión hacia abajo. Los miembros posteriores muy reducidos. El húmero presenta un largo surco bicipital. Íleon sublingual, tomando la forma de una varilla. Los huesos del carpo con tendencia a la fusión (Paula Couto, 1979).

\section{Dugongidae indet.}

Materiales y procedencia: Un diente. Zona norte chico, Caldera, Región de Atacama, Formación Bahía Inglesa (Bianucci et al., 2006).

Orden Cete Linnaeus, $1758^{1}$

Suborden Cetacea Brisson, 1762

Parvorder Odontoceti Flower, 1867

Superfamilia Physeteroidea Gill, 1872

Familia Physeteridae Gray, 1821

Cráneo con una marcada asimetría a nivel de los elementos óseos que rodean al conducto nasal. Gran expansión posterior del premaxilar derecho. En formas primitivas se observan dientes funcionales en el maxilar y mandíbula. En formas actuales sólo se presentan dientes funcionales en la mandíbula.

1 Esta propuesta incluye al suborden Acreodi, Matthew, 1909, que considera a Mesonychia Matthew, 1937 y Mesonychiformes Kinman, 1994 (McKenna \& Bell, 1997). 
Tabla 3.-Mioceno medio tardío-Plioceno temprano (12-5 millones de años)

\begin{tabular}{|c|c|c|c|c|c|c|}
\hline Orden & Suborden & Superfamilia & Familia & Subfamilia & Género & Especie \\
\hline \multirow[t]{2}{*}{$\dagger$ Notoungulata } & Typotheria & & Mesotheriidae & & Caraguatypotherium & $\begin{array}{l}\text { Caraguatypotherium } \\
\text { munozi }\end{array}$ \\
\hline & & & Hegetotheriidae & & Hegetotherium & $\begin{array}{l}\text { cf. Hegetotherium } \\
\text { torresi }\end{array}$ \\
\hline Pilosa & Phillophaga & $\dagger$ Megatheroidea & & & Thalassocnus & Thalassocnus sp. \\
\hline Uranotheria & Tethytheria & & $\dagger$ Dugongidae & & & Dugongidae indet \\
\hline \multirow[t]{13}{*}{ Cete } & Cetacea & Physeteroidea & Physeteridae & †oplocetinae indet & & \\
\hline & & & Kogiidae & & Kogia & Kogia sp. \\
\hline & & Delphinoidea & Delphinidae & & Delphinus & $\begin{array}{l}\dagger \text { Delphinus } \\
\text { domeykoi }\end{array}$ \\
\hline & & & & & Globicephala & Globicephala sp. \\
\hline & & & Phocoenidae & & & Phocenidae indet \\
\hline & & & $\dagger$ Pontoporiidae & & $\dagger$ Pliopontos & Pliopontos sp. \\
\hline & & & & & $\dagger$ Brachydelphis & Brachydelphis sp. \\
\hline & & & & & $\dagger$ Pontistes & Pontistes sp. \\
\hline & & & Balaenopteridae & & Balaenoptera & Balaenoptera sp. \\
\hline & & & Balaenidae & & Balaena & Balaena simpsoni \\
\hline & & & & & & Balaenidae indet \\
\hline & & & $†$ Cethoteriidae & & & Cethoteriidae indet \\
\hline & & & & & Morenocetus & Morenocetus sp. \\
\hline \multirow[t]{2}{*}{ Carnivora } & Feliformia & Phocoidea & Phocidae & & $\dagger$ Acrophoca & Acrophoca sp. \\
\hline & & & & & $\dagger$ Piscophoca & Piscophoca sp. \\
\hline $5(4 V+1 E)$ & $5(4 V+1 E)$ & $4(3 V+1 E)$ & $12(7 V+5 E)$ & & $14(5 V+9 E)$ & $18(5 V+13 E)$ \\
\hline
\end{tabular}

Subfamilia Hoplocetinae Cabrera, 1926

$\dagger$ Hoplocetinae indet. (este trabajo)

Materiales y procedencia: Un fragmento en el que se han conservado parte de los premaxilares, maxilares con piezas dentarias y ambas ramas mandibulares también con restos dentarios. Zona centro, ribera sur del río Rapel, al sureste del poblado Rapel, Región del Libertador Bernardo O'Higgins. Inicialmente Canto (2007) determinó este material sólo a nivel de superfamilia, sin embargo los antecedentes proporcionados por Hampe (2006) permiten posicionarlo dentro de la Subfamilia Hoplocetinae, por su cercanía anatómica a formas como Idiorophus patagonicus de Argentina (Cozzuol, 1996).

\section{Physeteroidea indet.}

Materiales y procedencia: Diente forma 1. Zona norte chico, Caldera, Región de Atacama, Formación Bahía Inglesa (Canto,
2007). Diente forma 2. Zona norte chico, Caldera, Región de Atacama, Formación Bahía Inglesa (Canto, 2007).

Familia Kogiidae (Gill, 1871) Miller, 1923

Los representantes de este grupo son los más pequeños de los Physeteroidea, alcanzando tamaños no mayores a cuatro metros. A nivel craneal se observa una depresión supracraneal muy distinta a los otros representantes de la superfamilia. Además la cabeza es más proporcionada en relación al tamaño del cuerpo (Meléndez, 1995).

\section{Kogia sp.}

Materiales y procedencia: El material corresponde a un periótico sin la bula timpánica. Zona norte chico, Caldera, Región de Atacama, Formación Bahía Inglesa (Canto, 2007). 
Superfamilia Delphinoidea Gray, 1821

Familia Delphinidae Gray, 1821

Agrupa a la mayoría de las especies de cetáceos actuales. Presentan dentición homodonta y muy numerosa, llegando hasta unas 260 piezas dentarias. El cráneo presenta una asimetría variable. Las vértebras cervicales están libres, excepto atlas y axis que se presentan soldadas entre sí. El rostro es alargado (en forma telescópica) (Paula Couto, 1979).

\section{$†$ Delphinus domeykoi Phillipi, 1887}

Materiales y procedencia: Fragmentos de una ulna y un radio. Zona centro, La Cueva Colchagua, Región del Libertador Bernardo O'Higgins. Restos de la misma especie son señalados para Constitución, Región del Maule (Oliver-Schneider, 1926).

\section{Globicephala sp.}

Materiales y procedencia: Un cráneo de $535 \mathrm{~mm}$ de longitud condilobasal. Zona centro, localidad de San Antonio, Región de Valparaíso. Preliminarmente fue asignado a este rango de edad en base al área del hallazgo (Brito \& Oporto, 1990).

\section{Famila Phocoenidae Gray, 1825}

Presentan una cabeza pequeña con un rostro corto. Piezas dentarias que varían entre 52 a 116, dependiendo de la especie. Cada diente presenta su corona comprimida en el sentido lateral. Los nasales presentan un marcado desarrollo y los pterigoídeos se presentan ensanchados (Barnes, 1985b).

\section{Phocenidae indet.}

Materiales y procedencia: Un cráneo de exposición dorsal conservado parcialmente, pero que permite visualizar los caracteres diagnósticos de la familia a nivel del premaxilar y nasales. Zona norte chico, Caldera, Región de Atacama, Formación Bahía Inglesa (Canto et al., 2002b).

\section{Familia Pontoporiidae Gray, 1870}

Escudo occipital toscamente cuadrado en vista posterior con ángulos dorsolaterales prominentes, no estrechos dorsalmente, porción de la maxila relativamente plana sin una gran pendiente inclinada posteriormente o bien lateralmente; porción rostral de la premaxila y maxila separada por un surco longitudinal lateral, rostro estrecho transversalmente desde su parte posterior hasta el final de la fila de dientes; zona posterior de la fila de alvéolos localizados en el borde lateral del palatino, curvándose hacia adelante del rostro por el extremo posterior; el paladar posterior es plano hasta el final de la hilera de alvéolos, maxila inferior con aspecto de crestas no neumatizadas sobre el orbital el que está orientado en un sentido anterolateral a postmedial y localizado antes del margen medial de la maxila; la fosa del seno pterigoidal posee láminas óseas que se extienden dorsalmente adyacente a la pared anterior de cada orificio nasal; los agujeros nasales son de diámetro pequeño y curvilíneos alrededor de la pared anterior de la base cerebral antes del adelgazamiento vertical, foramen pequeño de forma ovalada, diferente del hiato craneal, localizado sobre el hueso basioesfenoides sobre la pared del cráneo y confluente con el sulcus marcando la división mandibular del nervio trigémino; zigomático y proceso de la prolongación del escamoso terminado en punta inclinado anteriormente, proceso postglenoideo prominente orientado transversalmente.
Dientes comparativamente homodontes con coronas que poseen una protuberancia en su borde lingual y raíces que poseen un hinchamiento debajo de la línea de esmalte (Barnes, 1985a).

\section{$\dagger$ Pliopontos sp.}

Materiales y procedencia: Conjunto de vértebras cervicales, dorsales y lumbares. Zona norte chico, La Herradura, Región de Coquimbo, Formación Coquimbo (Canto et al., 2002a). Dos cráneos parciales, sin restos mandibulares. Zona norte chico, Caldera, Región de Atacama Formación Bahía Inglesa (Canto et al., 2002b).

\section{$\dagger$ Brachydelphis sp.}

Materiales y procedencia: Cinco cráneos con distinto grado de conservación, sin restos mandibulares asociados. Zona norte chico, Caldera, Región de Atacama, Formación Bahía Inglesa (Canto et al., 2002b). Estos restos amplían el rango de distribución del género en once grados de desplazamiento en latitud sur, ya que inicialmente sólo era reportado para Perú (Muizon, 1988).

\section{$\dagger$ Pontistes sp.}

Materiales y procedencia: Dos cráneos con distinto grado de conservación, sin restos mandibulares. Zona norte chico, Caldera, Región de Atacama, Formación Bahía Inglesa (Canto et $a l ., 2002 b$ ). Este género es señalado para Argentina, Cuenca del Paraná (Cabrera, 1926) en base a restos muy fragmentarios. Este registro amplía la distribución del género en el Neógeno del Pacífico Sur.

\section{Parvorder Mysticeti Cope, 1891 \\ Familia Balaenopteridae Gray, 1864}

Reúne a especies de gran tamaño. Cabeza pequeña con cráneo recto o muy ligeramente arqueado. Maxilares con proceso nasofrontal desarrollado; los nasales y las ramas nasales de los premaxilares no situados completamente por delante del nivel de las expansiones orbitales del frontal; ancho zigomático no más de dos veces el ancho de la base rostral; el proceso anterior del supraoccipital no sobrepasa anteriormente a las órbitas; las ramas mandibulares no se curvan fuertemente hacia afuera. Las vértebras cervicales se presentan libres (Reyes \& Molina, 1997).

\section{Balaenoptera sp.}

Materiales y procedencia: Restos de este género son reportados en base a vértebras. Zona sur, Estación Colico, antiguo ferrocarril a Curanilahue, Región de Arauco (Tamayo \& Frassinetti, 1980) y también para la isla Mocha (Oliver-Schneider, 1935). Otros restos vertebrales son señalados para la Zona norte chico, Caldera, Región de Atacama, Formación Bahía Inglesa (Canto et al., 2002b).

\section{Familia Balaenidae Gray, 1825}

Presentan un rostro ligera a fuertemente arqueado; maxilares sin proceso nasofrontal; los nasales y las ramas nasales de los premaxilares situadas completamente por delante del nivel de las expansiones orbitales del frontal; ancho zigomático al menos tres veces el ancho de la base rostral; el proceso anterior del supraoccipital sobrepasa anteriormente a las órbitas. Las 
ramas mandibulares son fuertemente curvadas. Las vértebras cervicales se presentan fusionadas (Reyes \& Molina, 1997).

\section{Balaena simpsoni Phillipi, 1887}

Materiales y procedencia: Fragmento craneal. Zona sur, localidad de Ancud, Región de Lagos. Este material fue descrito por Phillipi (1887). Posteriormente Oliver-Schneider, 1926, lo consigna como Neobalaena simpsoni. Sin embargo, los argumentos de este autor no son suficientes, por lo que mantenemos la designación de B.simpsoni hasta la revisión formal de tales materiales.

\section{Balaenidae indet.}

Materiales y procedencia: Fragmento craneal y vértebras. Zona norte chico, localidad de El Culebrón, Región de Coquimbo. Inicialmente Salinas (1988) asignó estos restos a la Familia Balaenopteridae; sin embargo, una revisión más detallada permitió determinar que se trataban de restos de un balénido (Yáñez \& Canto, 1991).

\section{Familia $†$ Cethoteriidae Cabrera, 1926}

Comprende sólo representantes fósiles de ballenas de tamaño pequeño, carentes de dientes en las que el proceso telescópico en la estructura del cráneo ya está presente. Parietales unidos entre sí a nivel de una cresta sagital. Los nasales y frontales están dispuestos de modo similar a los mamíferos terrestres. El supraoccipital se proyecta mucho menos sobre el cráneo, además el proceso supraorbital del frontal presenta un ángulo suave hacia el borde de los orbitales. Se observan unas depresiones conspicuas a nivel dorsal a cada lado del cráneo. (Paula Couto, 1979; Gaskin, 1985).

\section{Plesiocetopsis sp.}

Materiales y procedencia: Un cráneo con parte de una rama mandibular fusionada al cráneo. Zona centro, Rapel, Región del Libertador Bernardo O'Higgins (Tamayo \& Frassinetti, 1980).

\section{Morenocetus sp.}

Materiales y procedencia: Corresponde a una rama mandibular. Zona centro, Reñaca, Región de Valparaíso (Andrade, 1987; Andrade \& Jopia, 1988).

Orden Carnivora Bowdich, 1821

Familia Phocidae Gray, 1821

Sus representantes están adaptados a la vida acuática, la propulsión para la natación se realiza principalmente por la flexión del tronco. Poseen dentición heterodonta. Bula timpánica formada por un entotimpánico tan grande como el ectotimpánico (Morales \& Soria, 1990).

\section{$\dagger$ Acrophoca sp.}

Materiales y procedencia: Restos del esqueleto y parte del cráneo. Zona norte chico, Caldera, Región de Atacama (Walsh \& Naish, 2002).

\section{$\dagger$ Piscophoca $\mathrm{sp}$.}

Materiales y procedencia: Restos del esqueleto axial y parte del cráneo. Zona norte chico, Caldera, Región de Atacama (Walsh \& Naish, 2002).

\section{Pleistoceno-reciente (2,6 millones a 10,000 años AP) (tabla 4)}

Este es uno de los períodos de tiempo más documentados en lo referido a mamíferos fósiles, dado que no sólo son de interés paleontológico, sino que también de importancia para el ámbito de la arqueología. Podemos resumir en un conjunto de trabajos los aportes en el estudio de los mamíferos fósiles (Wyman, 1855; Casamiquela, 1968; Casamiquela \& Sepúlveda, 1974; Frassinetti \& Azcárate, 1974; Frassinetti, 1985; Frassinetti \& Salinas, 1986; Alberdi, 1987; Nami, 1987; Alberdi \& Prado, 1993; Borrero et al., 1997; Latorre, 1998; López et al., 2005).

\author{
Magnaorden Xenarthra Cope 1889, \\ nuevo rango McKenna \& Bell, 1997 \\ Orden Pilosa Flower, 1833 \\ Infraorden Megatheria McKenna \& Bell, 1997
}

La definición más reciente para este nuevo taxón indica que corresponde al ancestro más reciente de los Megatherioidea y Bradypodoidea y todos sus descendientes (McKenna \& Bell, 1997).

\section{Familia $†$ Megatheriidae Gray 1821}

Son gravígrados que pueden alcanzar un gran tamaño, similares en masa a los actuales elefantes. Sus miembros locomotores son robustos y cortos, observándose mayor desarrollo en los posteriores. Cráneo proporcionalmente pequeño en relación al tamaño del cuerpo. La dentición es característica del grupo; se disponen en dos series paralelas continuas, distantes del borde anterior de la mandíbula. Las piezas dentarias son hipsodontas y de sección prismática, con dos crestas transversales. El esqueleto es muy robusto. Clavícula fuerte. La escápula o coracoides se une con el acromión formando un puente óseo. La columna vertebral presenta articulaciones xenartras en la región posterior del tronco. La cintura pélvica es extremadamente grande (Paula Couto, 1979).

\section{Megatherium medinae Philippi, 1892}

Materiales y procedencia: Restos craneales, mandibulares y elementos vertebrales. Zona norte, Pica, Región de Arica y Parinacota; Chiuchiu, Región de Antofagasta; y Zona centro, Las Pozas (Chacabuco) y Lo Hermida, Región Metropolitana (Tamayo y Frassinetti, 1980); también en Cachagua, Zona centro, Región de Valparaíso (Frassinetti com. pers.).

Suborden Phyllophaga Owen, 1842

†Infraorden Mylodonta McKenna \& Bell, 1997

La definición más reciente para este taxón corresponde al más reciente ancestro común de Mylodontoidea y Orophodontoidea y todos sus descendientes.

\section{Familia Mylodontidae Ameghino, 1889}

Grupo muy diferenciado, de talla grande pero menor que Megatheriidae. Se caracteriza principalmente por la estructura de los dientes, los que presentan sección triangular o bilobulada, con la parte central deprimida y sin crestas transversales. Primer molar, cuando está presente, caniniforme. A nivel de extremidades se observa que la ulna es más corta que el radio. 
Tabla 4.-Pleistoceno-reciente (2, 6 millones de años - 10.000 años)

\begin{tabular}{|c|c|c|c|c|c|}
\hline Orden & Suborden & Superfamilia & Familia & Género & Especie \\
\hline \multirow[t]{5}{*}{ Cingulata } & & & $\dagger$ Megatheriidae & Megatherium & Megatherium medinae \\
\hline & Phyllophaga & & $†$ Mylodontidae & Glossotherium & Glossotherium lettsomi \\
\hline & & & & Mylodon & Mylodon darwini \\
\hline & & & & & Mylodon sp. \\
\hline & & & & Scelidodon & Scelidodon chiliense \\
\hline$\dagger$ Litopterna & & & Macraucheniidae & Macrauchenia & Macrauchenia sp. \\
\hline \multirow[t]{9}{*}{ Perissodactyla } & & & Equidae & $†$ Hippidion & Hippidion saldiasi \\
\hline & & & & & Hippidion principali \\
\hline & & & & & Hippidion sp. \\
\hline & & & & $\dagger$ Equus (Amerhipus) & Equus (Amerhipus) andium \\
\hline & & & & & Equus (Amerhipus) sp. \\
\hline & & & & & Equus sp. \\
\hline & & & & $\dagger$ †chnipus & Ichnipus cotaposi \\
\hline & & & Cervidae & $\dagger$ Antifer & Antifer niemeyeri \\
\hline & & & & Hippocamelus & Hippocamelus bisulcus \\
\hline \multirow[t]{3}{*}{ Rodentia } & Myomorpha & Muroidea & Muridae & Akodon & Akodon indet. \\
\hline & Hystricognatha & Octodontoidea & Octodontidae & & Myocastorinae Indet. \\
\hline & & & & Ctenomys & Ctenomys sp. \\
\hline \multirow[t]{2}{*}{$\dagger$ Proboscidea $^{1}$} & & & Gomphotheriidae & Cuvieronus & Cuvieronus hyodon \\
\hline & & & & Stegomastodon & Stegomastodon cf S. platensis \\
\hline \multirow[t]{8}{*}{ Carnivora } & Feliformia & & Felidae & Panthera & $\dagger$ Panthera onca mesembrina \\
\hline & & & & Smilodon & Smilodon populatur \\
\hline & & & & & Smilodon sp. \\
\hline & & & Mustelidae & & Mustelidae Indet \\
\hline & Caniformia & & Canidae & Pseudalopex & Pseudalopex culpaeus \\
\hline & & & & $\dagger$ Dusycion & Dusycion avus \\
\hline & & & & & Dusycion sp. \\
\hline & & & $\dagger$ Ursidae & Arctotherium & Arctotherium tarijense \\
\hline \multirow[t]{4}{*}{ Artiodactiyla } & Tylopoda & Cameloidea & Camelidae & $\uparrow$ Palaeolama & Palaeolama sp. \\
\hline & & & & Vicugna? & \\
\hline & & & & Lama & Lama guanicoe \\
\hline & & & & & Lama sp. \\
\hline Cete & & & Phocoenidae & Phocoena & Phocoena spinipinnis \\
\hline $8(6 V+2 E)$ & $6(6 \mathrm{~V}+0 \mathrm{E})$ & $3(3 \mathrm{~V}+0 \mathrm{E})$ & $14(11 V+5 E)$ & $23(7 V+16 E)$ & $31(9 \mathrm{~V}+22 \mathrm{E})$ \\
\hline
\end{tabular}

1 Para este grupo se siguió la nomenclatura de Mazo (1995). 
Tibia y peroné cortos, sin presentarse unidos (Paula Couto, 1979; Meléndez 1990).

Glossotherium lettsomi (Lydekker, 1887)

Materiales y procedencia: Restos óseos. Zona sur, Lonquimay, Región de la Araucanía (Tamayo \& Frassinetti, 1980).

\section{Mylodon darwini Owen, 1840}

Materiales y procedencia: Restos de piel, huesos dérmicos y restos del esqueleto axial y partes de cráneo. Zona austral, Cueva del Milodón (Cueva Eberhardt). También de Pali Aike y la gruta de Fell, ambos puntos de la Región de Magallanes (Tamayo \& Frassinetti, 1980).

\section{Mylodon sp.}

Materiales y procedencia: Restos de un trozo de piel, elementos costales, parte anterior de un cráneo, rama mandibular y piezas dentarias. Zona austral, Puerto Natales. También se mencionan restos de metápodos y huesecillos dérmicos, fragmentos craneanos y osteodermos de la cueva Los Chingues, ambos puntos de la Región de Magallanes (San Román et al., 2000). Otros restos son señalados para la Zona norte chico, Quereo, Los Vilos, Región de Coquimbo (Tamayo \& Frassinetti, 1980).

\section{Scelidodon chiliense (Lydekker, 1886)}

Materiales y procedencia: Un esqueleto casi completo, pero sin cráneo. Zona centro, Conchalí, Región Metropolitana (Tamayo y Frassinetti, 1980). Otros materiales son mencionados para la Zona norte, Pampa del Tamarugal, Región de Tarapacá (Oliver-Schneider, 1926).

\section{Scelidodon $\mathrm{sp}$.}

Materiales y procedencia: Un centro vertebral. Zona norte chico, Quereo, Los Vilos, Región de Coquimbo (Tamayo \& Frassinetti, 1980).

Orden $†$ Litopterna Ameghino, 1889

Familia Macraucheniidae Gervais, 1855

Corresponden a litopternos tridáctilos, mesaxónidos, con extremidades convergentes con las de los camellos. Cráneo generalmente bajo y alargado. Se evidencia un notable retraso progresivo de las aberturas nasales, que pueden alcanzar la parte superior del cráneo hasta situarse sobre las coanas, como ocurre, por ejemplo, en Macrauchenia (Alcalá \& Morales, 1995).

\section{Macrauchenia sp.}

Materiales y procedencia: Restos óseos. Zona norte chico, Tongoy, Región de Coquimbo. También varios huesos en la Zona centro, Las Pozas, (Chacabuco), Región Metropolitana (Tamayo \& Frassinetti, 1980). Una falange procedente de la Zona austral, Cueva del Milodón, Región de Magallanes (Oliver-Schneider, 1935).

\section{Orden Perissodactyla}

Familia Equidae Gray, 1821

Parte facial del cráneo alargado debido a la longitud de la serie dentaria yugal y al diastema. Desprovisto de cuernos. Nasales libres y que se proyectan hacia el frente, puntudos anteriormente. Dentadura completa (40 a 44 piezas); incisivos cinzeliformes; premolares más simples que los molares. A nivel de extremidades se puede observar, en formas fósiles, manos tetradáctilas y pies tridáctilos, con reducción progresiva del número de dedos, observándose en formas moderna sólo el tercer dedo, que se presenta bien desarrollado, con el metápodo muy alargado y falanges cortas, terminando la última en una estructura semicircular que soporta la uña. Los dedos laterales quedan muy reducidos (Paula Couto, 1979; Alberdi \& Cerdeño, 1995). Particularmente la Subfamilia Equinae (Gray, 1821) es un clado monofilético definido por cinco caracteres dentarios de acuerdo a Alberdi \& Prado (2004): «cemento permanente, presencia del pliegue caballino en los premolares y molares; presencia de pliegue en el linguafléxido; $\mathrm{P}_{2}$ con un ectofléxido moderadamente profundo y altura de la corona a nivel del $\mathrm{M}^{1-2}$ mayor que $23-28 \mathrm{~mm}$ ».

\section{$†$ Hippidion saldiasi Roth, 1899}

Materiales y procedencia: Un ejemplar casi completo con cráneo y mandíbula, húmeros, radios, fémures, tibias, metacarpos, astrágalos, calcáneos y falanges. Otros materiales son metacarpos. Zona norte, Calama, Región de Antofagasta (Alberdi et al., 2007); un metatarso del tercer dedo izquierdo, Zona centro, Santa Rosa de Chena, Región Metropolitana (Alberdi \& Frassinetti, 2000). Falanges. Zona austral, Cueva Lago Sofía, Cueva de la Ventana y Cueva del Medio; un calcáneo derecho, Cueva del Medio; un astrágalo derecho, Cueva de la Ventana; un fragmento facial, Cueva Los Chingues y un resto mandibular, Cueva de Fell. Todos estos hallazgos son para la Región de Magallanes (Alberdi \& Prieto, 2000).

\section{$\dagger$ Hippidion principale (Lund, 1846)}

Materiales y procedencia: Metatarso derecho del tercer dedo, un astrágalo derecho y calcáneo derecho, Zona centro, San Vicente de Taguatagua, Región Libertador Bernardo O'Higgins (Alberdi \& Frassinetti, 2000; Frassinetti \& Alberdi, 2001).

\section{$\dagger$ Hippidion sp.}

Materiales y procedencia: Se señalan materiales sin detalles para la Zona norte chico, Huallillinga, Ovalle, Región de Coquimbo; tres fragmentos de tibia y un resto de húmero izquierdo, Zona centro, Tierras Blancas, La Ligua, Región de Valparaíso; un metatarso central izquierdo, Zona centro, Santa Rosa de Chena; un fragmento de escápula, zona centro, Chacabuco, ambos registros de la Región Metropolitana; un $\mathrm{P}^{3-4}$ izquierdo roto, un metatarso derecho del tercer dedo, un fragmento de fémur de un individuo juvenil, un astrágalo derecho y un calcáneo derecho, Zona centro, San Vicente de Taguatagua, Región del Libertador Bernardo O'Higgins (Alberdi \& Frassinetti, 2000).

\section{Equus (Amerhippus) andium Branco, 1883 ex Wagner, 1860}

Materiales y procedencia: Un $\mathrm{M}^{1-2}$ derecho de talla pequeña, Zona norte chico, Valle de Elqui, Región de Coquimbo (Prado \& Alberdi, 1994). Un $\mathrm{M}^{1-2}$ derecho en el que está presente el protocono característico, Zona centro, Lo Aguirre, Calera, Región de Valparaíso (Alberdi \& Frassinetti, 2000).

\section{$†$ Equus (Amerhippus) sp.}

Materiales y procedencia: Dientes superiores e inferiores; restos de una rama mandibular derecha; elementos del esquele- 
to apendicular (falanges y un calcáneo) y una diáfisis del fémur, Zona centro, Chacabuco, Región Metropolitana. Un acetábulo de pelvis, Zona norte chico, Los Vilos, Región de Coquimbo. Un $\mathrm{P}^{3-4}$ roto, Zona centro, San Vicente de Taguatagua, Región del Libertador Bernardo O’Higgins. Un $\mathrm{M}^{3}$ izquierdo, Zona centro, Huimpil, Región del Libertador Bernardo O'Higgins. (Alberdi \& Frassinetti, 2000).

\section{Equus sp.}

Materiales y procedencia: Piezas dentarias de un mismo individuo. Zona centro, San Bernardo, Región Metropolitana (Alberdi \& Frassinetti, 2000).

\section{†Ichnipus cotaposi Casamiquela y Chong, 1975}

Materiales y procedencia: Este registro reviste la particularidad de ser una evidencia representada por icnitas. Zona norte, La Chimba, Región de Antofagasta.

\section{Familia Cervidae Goldfuss, 1820}

Cráneo con grandes protuberancias óseas, principalmente en los machos, denominadas genéricamente astas, las que se forman desde una parte basal cilíndrica que se fusiona a los frontales, por encima de las órbitas. Bulas timpánicas pequeñas y ligadas al cráneo. A nivel dental, canino superior presente en machos y hembras; canino inferior incisiviforme. Diastema anterior amplio. Serie de premolares superiores e inferiores selenobraquiodontos. Huesos del carpo y tarso parcialmente osificados; metapodios (III y IV) soldados (Paula Couto, 1979).

Tribu Odocoileini Pocock, 1923

$\dagger$ Antifer niemeyeri Casamiquela, 1984

Materiales y procedencia: Una cornamenta parcial. Zona centro, San Vicente de Taguatagua, Región del Libertador Bernardo O’Higgins (Casamiquela, 1984; Núñez et al., 1994). Originalmente este material fue señalado por Tamayo \& Frassinetti (1980) como Antifer sp.

\section{$\dagger$ Antifer $\mathrm{sp}$.}

Materiales y procedencia: Una cornamenta casi completa, Zona norte chico, Los Vilos, Región de Coquimbo (Labarca \& López, 2006).

\section{Hippocamelus bisulcus (Molina, 1782)}

Materiales y procedencia: Sólo se menciona el registro sin detalles de los materiales. Zona centro, Las Pozas, Chacabuco, Región Metropolitana (Tamayo \& Frassinetti, 1980). Restos vertebrales, Zona austral, Cueva Baño Nuevo, Región de Aisén (Velásquez \& Mena, 2006).

Orden Rodentia Bowdich, 1821

Suborden Myomorpha Brandt, 1855

Superfamilia Muroidea Illiger, 1811

Familia Muridae Illiger, 1811

Presentan molares con cúspides laminares o prismas; las cúspides se ordenan en dos hileras. No presentan premolares ni caninos. Fórmula dentaria $\mathrm{I}_{1}^{1}, \mathrm{C}_{0}^{0}, \mathrm{P}_{0}^{0} \mathrm{M}^{3}{ }_{3}$ Abertura infraorbital dividida con la parte superior redondeada. Frontales sin apófisis. Placa zigomática grande e inclinada hacia arriba. (Muñoz \& Yáñez, 2000).

\section{Akodon indet.}

Materiales y procedencia: Sólo se menciona el registro sin detalles de los materiales. Zona austral, Última Esperanza, Cueva del Milodón, Región de Magallanes (Tamayo \& Frassinetti, 1980).

Suborden Hystricognatha Woods, 1976

Superfamilia Octodontoidea Waterhouse, 1839

Familia Octodontidae Waterhouse, 1839

Grupo antiguo que presenta molares con repliegues, otorgando la apariencia de ocho a la superficie oclusal de los molares (Muñoz \& Yáñez, 2000).

Myocastorinae Ameghino, 1902

Myocastorinae Indet.

Materiales y procedencia: Sólo se menciona el registro sin detalles de los materiales. Zona centro, San Vicente de Taguatagua, Región del Libertador Bernardo O'Higgins. Inicialmente los materiales fueron asignados por Tamayo \& Frassinetti (1980) a la Familia Myocastoridae, pero de acuerdo a la propuesta de McKenna \& Bell (1997), queda en la categoría de subfamilia.

\section{Ctenomys sp.}

Materiales y procedencia: Sólo se menciona el registro sin detalles de los materiales y se presentan asociados a fragmentos de Megatherium medinae. Zona norte, Pampa del Tamarugal, Región de Tarapacá (Tamayo \& Frassinetti, 1980).

Orden Proboscidea Illiger, 1811

Superfamilia Elephantoidea Gray, 1821

Familia Gomphotheriidae Hay, 1922

Incluye a la mayor parte de los mastodontes bunodontos, constituyéndose en el grupo más diversificado de los proboscideos. En general presentan un cráneo bajo y alargado; incisivos superiores curvados hacia abajo y hacia fuera, con banda de esmalte; sínfisis mandibular longirostrina o medilongirostrina. Incisivos de sección piriforme y dientes intermedios trilofondontos (Mazo, 1995).

Tribu †Cuvieroniini Cabrera 1926

Cuvieronus hyodon (Fisher, 1814)

Materiales y procedencia: Piezas dentarias y restos de defensas procedentes de las Zonas norte, norte chico, centro y sur (Tamayo \& Frassinetti, 1980; Moreno et al., 1991; Frassinetti $\&$ Alberdi, 2000). Es necesario una reevaluación de la asignación de estos fósiles, ya que de acuerdo al trabajo de Frassinetti \& Alberdi (2005) el sustento de esta especie es débil, como se ha visto para los materiales de San Vicente de Taguatagua, que han sido reinterpretados, reuniéndolos en un género diferente (Stegomastodon cf. S. platensis).

\section{Stegomastodon cf. S. platensis Ameghino, 1888}

Materiales y procedencia: Una defensa casi completa; un fragmento de defensa; una parte anterior de la sínfisis craneal o zona alveolar de las defensas. Zona centro, San Vicente de Taguatagua, Región del Libertador Bernardo O'Higgins. Otros materiales son referidos a un fragmento de cráneo que conserva 
el maxilar con $\mathrm{M}^{2}$ y $\mathrm{M}^{3}$ derechos e izquierdos de ambas defensas, Zona centro, Tierras Blancas, La Ligua. Región de Valparaíso. Un fragmento de defensa, Zona centro, Chacabuco, Región Metropolitana. Una defensa, Zona centro, Batuco, Región Metropolitana. Fragmentos de una defensa, Zona centro, Marchigüe, Región del Libertador Bernardo O'Higgins. Parte de una defensa y restos dentarios, Zona sur, Monte Verde, Región de Los Lagos (Frassinetti \& Alberdi, 2005). Es importante mencionar que tradicionalmente la literatura reportaba la existencia de Cuvieronus humboldtii (Tamayo \& Frassinetti, 1980); nuevos trabajos indican que, por ahora, no es posible sustentar dicha especie (Frassinetti \& Alberdi, 2005).

Orden Carnivora Bowdich, 1821

Suborden Feliformia Kretzoi, 1945

Familia Felidae Fisher de Waldheim, 1817

Presentan dentición cortante muy especializada; las series premolar y molar fuertemente reducidas; carniceros y caninos fuertes. Cráneo redondeado con arcos zigomáticos fuertes. Bulas timpánicas globosas, internamente divididas por un septum, sin canal aliesfenoide. Miembros digitígrados con garras retráctiles (Morales \& Soria, 1990).

\section{$†$ Panthera onca mesembrina Cabrera, 1934}

Materiales y procedencia: Restos mandibulares y un metapodio. Zona austral, Cueva del Milodón, Última Esperanza, Región de Magallanes (Tamayo \& Frassinetti 1980; Nami \& Menegaz 1991).

\section{†cf. Panthera onca mesembrina Cabrera, 1934}

Materiales y procedencia: Quinto metatarso izquierdo y dos falanges. Zona norte chico, Quereo, Región de Coquimbo (López, 2007).

\section{$\uparrow$ Smilodon populator (Lund, 1842)}

Materiales y procedencia: Restos de cráneos y huesos del esqueleto axial colectados entre 1908 y 1909 para el Museo de Ámsterdam. Zona austral, Cueva de Última Esperanza, Puerto Natales, Región de Magallanes (Mol et al., 2003).

\section{$\dagger$ Smilodon sp.}

Materiales y procedencia: Un fragmento premaxilar izquierdo fuertemente erosionado, que ha conservado parcialmente dos piezas dentarias. Zona austral, Cueva Lago Sofía 4, Última Esperanza, Región de Magallanes (Canto, 1991)

\section{Familia Mustelidae Fisher de Waldheim, 1817}

Cráneo con fosa suprameatal oculta en el proceso mastoideo; pérdida del canal aliesfenoides y oído medio derivado del tipo prociónido. $\mathrm{M}^{2}$ reducido, ausente en la mayoría de los géneros. Fuerte tendencia al acortamiento del $\mathrm{P}^{4}$, el que pierde la incisión que marca la separación protocono-metastilo (Morales \& Soria, 1990).

\section{Mustelidae Indet.}

Materiales y procedencia: Sólo se menciona el registro sin detalles de los materiales. Roth en 1899 los determinó como Conepatus suffocans, especie no presente en Chile, sin embar- go, si la determinación a nivel de género es correcta podría tratarse de $C$. humboldti. Cabe señalar que otros autores mencionan este material como Lyncodon patagonicus. Zona austral, Cueva de Eberhard, Región de Magallanes (Tamayo \& Frassinetti, 1980).

Suborden Caniformia Kretzoi, 1943

Infraorden Cynoidea Flower, 1869

Familia Canidae Fisher de Waldheim, 1817

Poseen dentición completa $\mathrm{I}_{3}^{3} \mathrm{C}_{1}^{1} \mathrm{P}_{4}^{4} \mathrm{M}_{3}^{3}$. El M $\mathrm{M}_{1}$ con trigónido alto en relación al talónido; protocono prominente en el $\mathrm{P}^{4}$, cíngulo continuo alrededor del protocono de los molares superiores. Bulas timpánicas sin osificar (Morales \& Soria, 1990)

Pseudalopex culpaeus (Molina, 1782)

Materiales y procedencia: Sólo se menciona el registro sin detalles de los materiales. Proceden de dos sectores de la Zona austral: Cueva del Medio y la Cueva de Fell (Frassinetti \& Alberdi, 2001).

\section{$\dagger$ Dusycion avus Burmeister, 1879}

Materiales y procedencia: Una mitad de un maxilar, dos molares y la mandíbula. Zona austral, Última Esperanza, Cueva del Milodón, Región de Magallanes (Oliver-Schneider, 1926; Tamayo \& Frassinetti, 1980).

\section{$†$ Dusycion cf avus Burmeister, 1879}

Materiales y procedencia: Astrágalo izquierdo y $\mathrm{M}^{2}$ derecho. Zona norte chico, Quereo, Región de Coquimbo (Labarca \& López, 2006).

\section{$\dagger$ Dusycion sp.}

Materiales y procedencia: Restos fósiles sin detallar la composición de materiales, mencionados como Canis (Dusicyon sp.) por Tamayo \& Frassinetti (1980). Zona norte, Pampa del Tamarugal, Región de Tarapacá.

Canidae indet.

Restos fósiles sin detallar la composición de materiales (Tamayo \& Frassinetti, 1980). Zona centro, Chacabuco, Región Metropolitana y San Vicente de Taguatagua, Región del Libertador Bernardo O'Higgins.

\section{Familia Ursidae Fisher de Waldheim, 1817}

Cráneo con bula timpánica formada únicamente por un entotimpánico pequeño en comparación con el ectotimpánico; procesos paroccipital y mastoidiano unidos por una cresta ósea fuerte. Entrada del canal carotidiano por el foramen yugal (Morales \& Soria, 1990).

\section{Arctotherium tarijense Ameghino, 1902}

Materiales y procedencia: Un fémur procedente de la Cueva del Milodón, Región de Magallanes, asignado a Arctotherium sp. por Smith Woodward en 1900 y posteriormente determinado como Pararctotherium pamparum por Oliver-Schneider (1935). Este material posteriormente se extravió. El descubrimiento de un incisivo en la Cueva de Los Chingues, Región de 
Magallanes de Arctotherium (Pararctotherium) por San Román et al., 2000 y Prevosti et al., 2003 confirmó la presencia de este género en la parte austral de Chile. La revisión realizada por Soibelzon (2004) indica que los materiales deben ser reconocidos como Arctotherium tarijense, quedando Pararctotherium en calidad de sinonimia.

Orden Artiodactiyla Owen, 1841

Suborden Tylopoda Illiger, 1811

Superfamilia Cameloidea Gray, 1821

Familia Camelidae Gray, 1821

Cráneo con órbitas cerradas; bula timpánica voluminosa, rellena de hueso esponjoso. Se observa tendencia al desarrollo de diastemas en la dentición anterior. Predisposición al alargamiento de las extremidades y a la reducción y fusión de los metápodos y dedos (Morales \& Soria, 1995).

Tribu Lamini Webb, 1965

$\dagger$ Palaeolama sp.

Materiales y procedencia: Restos fragmentarios. Zona norte chico, Quereo, Región de Coquimbo Recientemente López (2007) reporta restos de un basicráneo procedente de la misma localidad. Otros materiales proceden de la Zona central, Chacabuco, Región Metropolitana y la Zona sur, Malleco y Osorno, Región de la Araucanía (Frassinetti \& Alberdi, 2001).

\section{Vicugna?}

Materiales y procedencia: Un incisivo. Zona austral, Cueva Lago Sofía 4 y Tres Arroyos, Última Esperanza, Región de Magallanes (Prieto \& Canto, 1997).

Lama guanicoe (Muller, 1776)

Materiales y procedencia: Restos de extremidades. Zona austral, Cueva Los Chingues, Región de Magallanes (San Román et al., 2000). También son señalados restos, sin mencionar a qué corresponden. Proceden de la Cueva del Milodón (OliverSchneider, 1935), y están depositados en el Museo de la Plata (Argentina).

Lama sp.

Materiales y procedencia: Sólo se menciona el registro sin detalles de los materiales. Zona norte, Pica, Pampa del Tamarugal, Región de Tarapacá. Registro sin detalles, Zona sur, Los Sauces, Malleco, Región de la Araucanía (Tamayo \& Frassinetti, 1980). Registro sin detalles, Zona austral, Cueva del Medio y Cueva Lago Sofía 4 (Frassinetti \& Alberdi, 2001).

Orden Cete Linnaeus, $1758^{2}$

Suborden Cetacea Brisson, 1762

Parvorder Odontoceti Flower, 1867

Familia Phocoenidae Gray, 1825

Phocoena spinipinnis

Material y procedencia: Un cráneo sin mandíbula. Zona sur, Concepción, Región del Biobío (Yáñez et al., 1994).

\section{Discusión}

\section{Interpretación del registro fósil de los mamíferos en Chile}

El registro fósil de mamíferos en Chile es uno de los más extensos en relación a los otros grupos de vertebrados en el territorio nacional (Canto \& Frassinetti, 2008). Esta situación podría obedecer a que los eventos tectónicos de envergadura, tales como la separación de América del Sur de África, ocurrida en el Cretácico - Paleoceno, y el mayor pulso de elevación de los Andes, alcanzado durante el Plioceno (Hinojosa \& Villagrán, 1997; Charrier et al., 2007), favorecieron la existencia de rangos de tiempo con una actividad orogénica menor, lo que podría otorgar una mayor probabilidad a los procesos de fosilización y conservación de los restos óseos de mamíferos en la mayor parte del territorio.

De lo anterior se desprende que la concentración de restos fósiles está relacionada en forma íntima con las posibilidades efectivas de conservación in situ, y/o con una condición tafonómica alterada (redepositación del material) mínima. En este sentido las zonas del país en que se han presentado la mayor cantidad de hallazgos podrían responder a adecuadas condiciones de fosilización de los restos y su posterior conservación, especialmente entre el Oligoceno y Plioceno.

Junto a lo anterior, un aspecto relevante está dado por la distribución porcentual de hallazgos de fósiles en las distintas zonas geográficas del país, que podría obedecer a tres aspectos: $a$ ) un sesgo determinado por el esfuerzo de captura de datos (Región de Atacama, Zona norte chico y la Región de Aysén y Región de Magallanes, Zona austral); $b$ ) una zona de hallazgos frecuentes, debido a la alta concentración de actividad antrópica, como por ejemplo parte de la Zona centro (en particular el caso de la Región del Libertador Bernardo O'Higgins, especialmente en el área del Cachapoal y a lo largo de la costa) y c) búsqueda sistemática de fósiles; esta situación es aplicable al caso de los materiales fósiles que proceden del interior de la Quebrada Chucal (Zona norte), sector que presenta un rico ensamble de mamíferos terrestres de una antigüedad de entre 22,5 a 17 millones de años y cuyo descubrimiento obedece claramente a una búsqueda intencionada.

\footnotetext{
2 Esta propuesta incluye al suborden Acreodi, Matthew, 1909, que considera a Mesonychia Matthew, 1937 y Mesonychiformes Kin-
} man, 1994 (McKenna \& Bell, 1997). 
Esto pone de manifiesto que la exploración dirigida a la búsqueda de restos fósiles puede proporcionar nuevos materiales dentro de zonas geográficas con menos investigación, así como aquellas que son conocidas por su cantidad y diversidad de restos de mamíferos fósiles.

Cabe señalar que no sólo los procesos orogénicos tuvieron una amplia significancia en las posibilidades de desarrollo evolutivo y ocupación por parte de los mamíferos terrestres, sino que también las secuencias de transgresiones ocurridas entre Mioceno inferior hasta la base del Mioceno superior (19 a 10 millones de años; secuencia inferior SNPSO-I) y la desarrollada en el Plioceno superior (3,5 a 1,6 millones de años; secuencia superior SNPSO-II), (Martínez, 1990) en la costa pacífica oriental.

Esta última situación tuvo un fuerte impacto en la evolución y diversificación, especialmente de las faunas de mamíferos marinos distribuidas ampliamente a lo largo de la costa de Chile, con especial recurrencia en la costa de Zona norte (Arica a Antofagasta) y Zona norte chico (Caldera a Coquimbo). La expansión de estas faunas podría haber obedecido a dos factores: a) la apertura de nuevos nichos ecológicos a nivel de franja costera, permitiendo la evolución y desarrollo de nuevas especies, y $b$ ) el establecimiento de un nuevo sistema de corrientes marinas que coinciden con la apertura del paso Drake y la deriva hacia el norte de la Convergencia Intertropical (ITCZ) (Fordyce, 1977; Hinojosa \& Villagrán, 1997), con las implicancias que esto trae aparejado en lo relativo a la oferta trófica, especialmente en poblaciones de ballenas, delfines, focas y lobos marinos (Gaskin, 1985).

\section{Distribución de los descubrimientos paleontológicos de mamíferos fósiles por zona geográfica}

La distribución de las faunas presenta su mayor diversidad en el Mioceno inferior - Mioceno medio abarcando la mayor cantidad de géneros y especies. Los ambientes terrestres se caracterizan por presentarse con un predominio tipo parque o sabana arbolada. Sudamérica se presenta completamente aislada, asociada a un óptimo climático (Ortiz-Jaureguizar \& Cladera, 2006), situación que pudo contribuir a la amplia diversificación de especies dada la estabilidad ambiental. Complementariamente Hinojosa \& Villagrán (1997) documentan que en Chile en el Mioceno medio a superior suceden varios eventos geológicos que sin duda impactaron sobre la evolución y diversidad de faunas de mamíferos pasados y presentes.

\section{Familias y géneros por época}

(tablas 1, 2, 3, 4 y 5; figuras 2, 3 y 4)

En términos de diversidad paleontológica de mamíferos es interesante notar que la mayor diversidad de géneros, así como de especies, está presen-

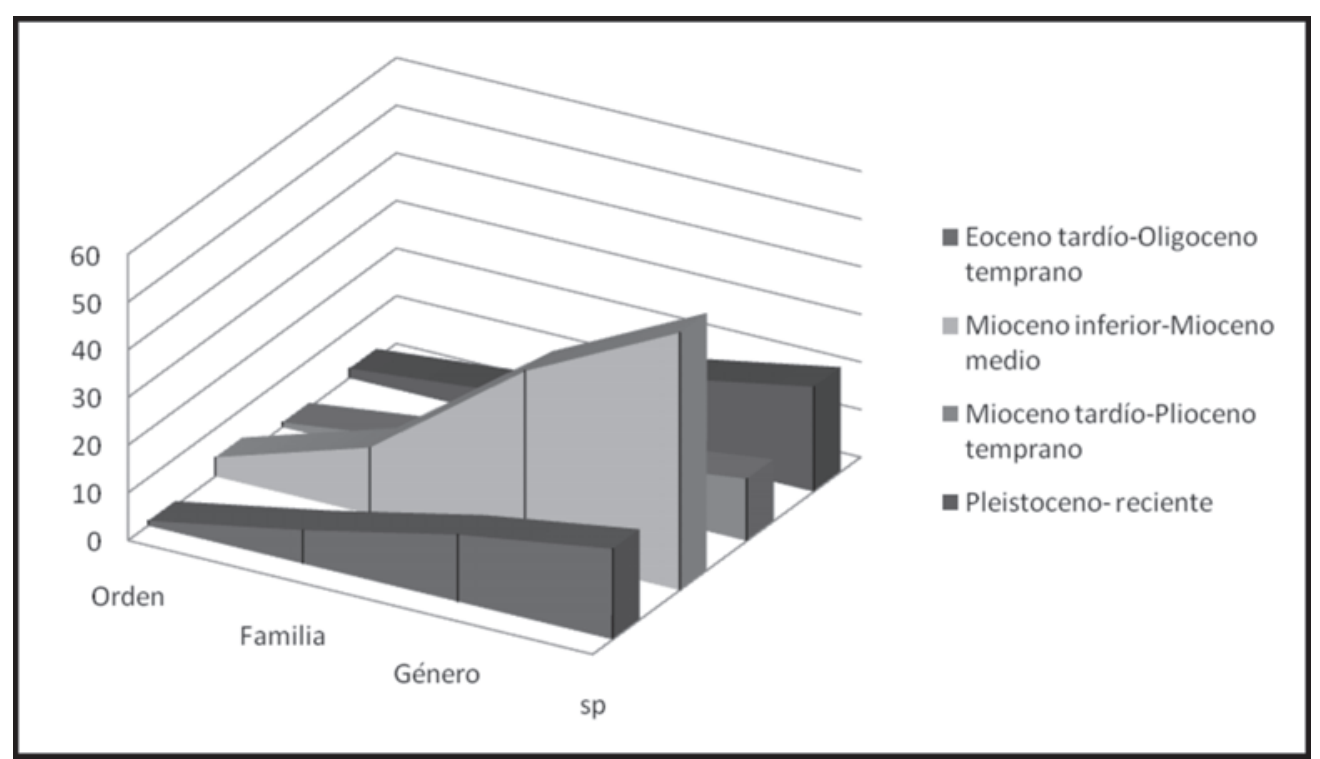

Fig. 2.-Distribución de categorías taxonómicas de mamíferos fósiles en Chile por período. Los valores para cada categoría son presentados en la tabla 5 . 


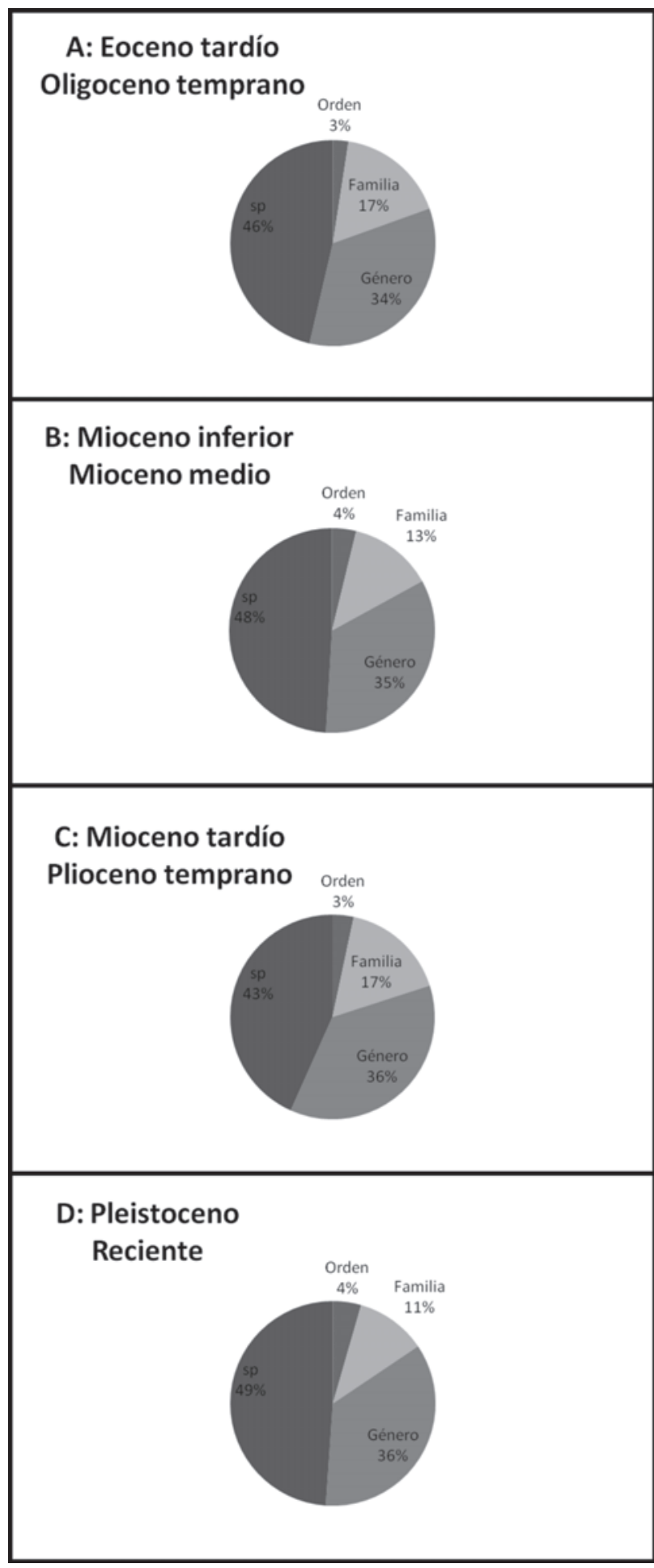

Fig. 3.-Distribución de taxones por rango de tiempo. Se evidencia que a pesar de que existen diferencias en el número de taxones por categoría, se mantienen dentro de una distribución porcentual similar para cada agrupación (orden, familia, género y especie).

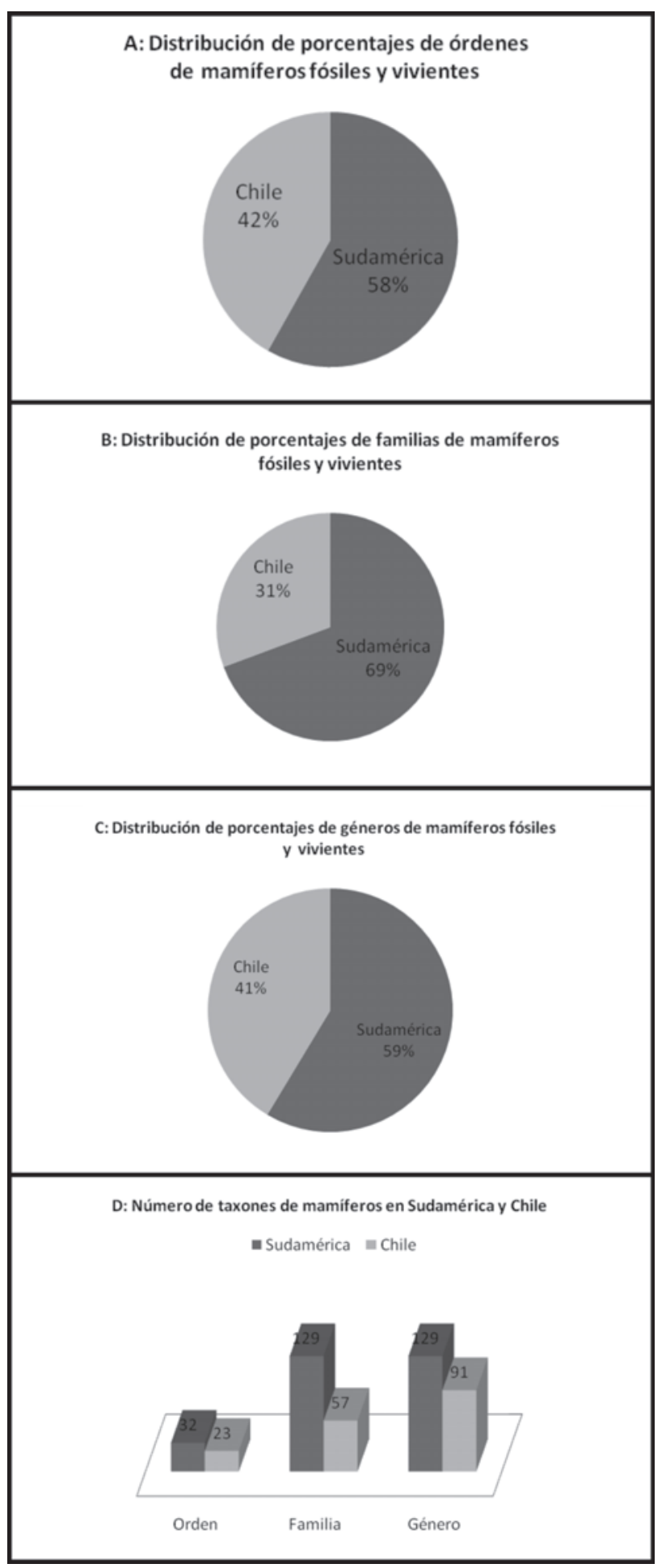

Fig. 4.-Comparación porcentual de los taxones de los mamíferos presentes en Chile y Sudamérica desde el Cretácico hasta el presente. Los datos de Sudamérica son aportados por Pascual et al. (1996) y Cozzuol (1996). Se evidencia que el registro fósil de Chile es significativo en relación al resto de Sudamérica, especialmente a nivel de la categoría taxonómica orden, que presenta una menor diferenciación de porcentajes en relación al resto de los taxones. 
Tabla 5.-Distribución de taxones extintos y vivientes de mamíferos fósiles por rango de tiempo

\begin{tabular}{|c|c|c|c|c|c|c|}
\hline Rango de Tiempo & Orden & Suborden & Superfamilia & Familia & Género & Especie \\
\hline ¿Eoceno tardío?-Oligoceno temprano & $2(1 \mathrm{~V}+1 \mathrm{E})$ & $2(2 \mathrm{~V})$ & & $8(1 \mathrm{~V}+7 \mathrm{E})$ & $14(14 \mathrm{E})$ & 19(19E) \\
\hline Mioceno inferior-Mioceno medio & $8(4 V+4 E)$ & $3(1 \mathrm{~V}+2 \mathrm{E})$ & $6(4 V+2 E)$ & $23(10 V+13 E)$ & $39(1 \mathrm{~V}+38 \mathrm{E})$ & $54(54 \mathrm{E})$ \\
\hline Mioceno tardío-Plioceno temprano & $5(4 V+1 E)$ & $5(4 V+1 E)$ & $4(3 \mathrm{~V}+1 \mathrm{E})$ & $12(7 V+5 E)$ & $14(5 V+9 E)$ & $18(5 \mathrm{~V}+13 \mathrm{E})$ \\
\hline Pleistoceno-reciente & $8(6 \mathrm{~V}+2 \mathrm{E})$ & $6(6 \mathrm{~V}+0 \mathrm{E})$ & $3(3 \mathrm{~V}+0 \mathrm{E})$ & $14(11 \mathrm{~V}+5 \mathrm{E})$ & $23(7 V+16 E)$ & $31(9 \mathrm{~V}+22 \mathrm{E})$ \\
\hline
\end{tabular}

V: Taxón viviente E: Taxón extinto

te entre Mioceno inferior al Mioceno medio (tabla 2), con un total reportado de 38 géneros todos extintos. Esto representa un $48,7 \%$ en relación a todos los géneros fósiles de mamíferos registrados para Chile. A nivel de las especies fósiles se registran un total de 54 , lo que representa un $51,4 \%$ con respecto al total de las mencionadas. La menor cantidad de géneros y especies está dada en el rango Mioceno tardío-Plioceno temprano, con un total de 9 géneros extintos, lo que representa un $10 \%$ con respecto al total y para el caso de las especies, 13 extintas representando un $12,3 \%$ del total (fig. 2).

Es interesante notar que la proporción numérica para las categorías: orden, familia, género y especie es muy similar en la composición de los mamíferos reportados para los cuatro rangos de tiempo (fig. 3). Cabe señalar que el valor de mayor frecuencia se evidencia en las categorías de orden y género fluctuando en uno y dos puntos (3\% a $4 \%$ y $34 \%$ a $36 \%$ respectivamente). Para los taxones familia y especie los valores se mueven en dos o tres puntos porcentuales. A este respecto Gould (1983) hace mención a una experimentación y estandarización temprana en los mamíferos, situación que puede ser pensada para las faunas de mamíferos fósiles en Chile. Esto deja abierta la posibilidad de revisar si las faunas de Chile se ajustan a una composición estructurada con una alta diversidad en niveles supragenéricos y especies con bajo grado de diferenciación anatómica, de aquellas compuestas de un nivel de baja diversidad supragenérica y especies con alta diferenciación anatómica, situación planteada por Pascual y Ortiz-Jaureguizar (2007).

En términos de la relación porcentual el registro de mamíferos de Chile en relación a los datos proporcionados por Pascual et al. (1996) y Cozzuol (1996) para el resto de Sudamérica indican que a nivel de orden la distribución porcentual es la que varía en menor rango ( $42 \%$ en Chile y $58 \%$ en Sudamérica).

A nivel de familia se observa la mayor variación porcentual (31\% en Chile y $69 \%$ en Sudamérica).
Para el nivel de especie la relación es $41 \%$ en Chile y $59 \%$ en Sudamérica, muy similar a la observada en la categoría de orden.

Los nuevos hallazgos de fósiles de mamíferos, indicados en esta revisión, permiten pensar que, en la medida que se realicen nuevos estudios de campo y la búsqueda de los restos sea más sistemática, surgirán nuevos descubrimientos que, en muchos casos podrán ser sorprendentes y posiblemente nos permitan desarrollar nuevas ideas acerca de los procesos evolutivos seguidos por los mamíferos en Sudamérica y en Chile. El aumento de los trabajos en los últimos años y una actividad paleontológica incrementada en el país (Primer Congreso Latinoamericano de Paleontología de Vertebrados 2002, Primer Simposio de Paleontología en Chile 2008), permiten una mirada de confianza y optimismo para el desarrollo de la disciplina en Chile.

\section{AGRADECIMIENTOS}

Un agradecimiento especial a Richard Fariña de la Universidad La República, Uruguay, por sus valiosos comentarios y aportes en torno a este trabajo. De igual forma a José L. Prado de la Universidad Nacional del Centro de la Provincia de Buenos Aires, Argentina por sus ideas y discusión inicial de este trabajo. Daniel Frassinetti del Museo Nacional de Historia Natural de Santiago, Chile contribuyó con su experiencia y puso a nuestro alcance bibliografía. Nuestra gratitud a los revisores Dr. Alfredo Zurita (Argentina) y Dra. María Teresa Alberdi (España) que ayudaron significativamente a mejorar el manuscrito.

\section{Referencias}

Alberdi, M.T. (1987). La familia Equidae, Gray, 1821 (Perissodactyla: Mammalia) en el Pleistoceno de Sudamérica. IV Congreso Latinoamericano Paleontología, Bolivia, 1: 484-499.

Alberdi, M.T. \& Prado, J.L. (1993). Review of the genus Hippidion Owen, 1869 (Mammalia: Perissodactyla) from the Pleistocene of the South America. Zoological Journal of the Linnean Society, 108: 1-22. doi:10.1111/j.10963642.1993.tb02559.x 
Alberdi, M.T. \& Cerdeño, E. (1995). Perisodáctilos. In: Paleontología: Mamíferos, $2^{\text {a }}$ parte (Meléndez, B., Ed.). Editorial Paraninfo, Madrid, 91-153.

Alberdi, M.T. \& Frassinetti, D. (2000). Presencia de Hippidion y Equus (Amerhippus) (Mammalia: Perissodactyla) y su distribución en el Pleistoceno Superior de Chile. Estudios Geológicos, 56: 279-290. doi:10.3989/egeol.00565-6144

Alberdi, M.T. \& Prieto, A. (2000) Hippidion (Mammalia, Perissodactyla) de las cuevas de las provincias de Magallanes y Tierra del Fuego. Anales del Instituto de la Patagonia, Serie Ciencias Humanas, 28: 147-171.

Alberdi, M.T. \& Prado, J.L. (2004). Caballos fósiles de América del Sur. Incuapa, Universidad Nacional del Centro de la Provincia de Buenos Aires, Argentina, $269 \mathrm{pp}$.

Alberdi, M.T.; Prado, J.L.; López, P.; Labarca, R. \& Martínez, I. (2007). Hippidion saldiasi Roth, 1899 (Mammalia, Perissodactyla) en el Pleistoceno tardío de Calama, norte de Chile. Revista Chilena de Historia Natural, 80: 157-171. doi:10.4067/S0716-078X2007000200003

Alcalá, L. \& Morales, J. (1995). Ungulados sudamericanos. In: Paleontología 3: Mamíferos, 2- ${ }^{\text {a }}$ parte (Meléndez, B., Ed.). Editorial Paraninfo, Madrid, 161-219.

Alférez, F. (1990). Mamíferos. In: Paleontología 3: Mamíferos, $1^{\text {a }}$ parte (Meléndez, B., Ed.), Editorial Paraninfo, Madrid, 1-24.

Andrade, V. (1987). La ballena fósil de Reñaca. Boletín Museo Sociedad Fonck, 6, noviembre, 1 pp.

Andrade, V. \& Jopia, H.R. (1988). Descubrimiento de un cetáceo fósil del género Morenocetus encontrado en Reñaca, Quinta Región Chile. In: $1^{\circ}$ Taller Sobre Conservación y Manejo de Mamíferos Marinos de Chile, 19-20 de agosto de 1988, Valdivia, Chile.

Barnes, L.G. (1985a). Fossil pontoporid dolphins (Mammalia: Cetacea) from the Pacific coast of north american. Contributions in Science, Natural History Museum of Los Angeles, 363: 1-34.

Barnes, L.G. (1985b). Evolution, taxonomy and antitropical distributions of the torpoises (Phocoenidae: Mammalia). Marine Mammal Science, 1: 149-165. doi:10.1111/j.1748-7692.1985.tb00003.x

Barnes, L.G.; Domning, D.P. \& Ray, C.E. (1985). Status of studies on fossil Marine Mammals. Marine Mammal Science, 1: 15-53. doi:10.1111/j.17487692.1985.tb00530.x

Bianucci, G.; Sorbi, S.; Suárez, M. \& Landini, W. (2006). The southernmost sirenian record in the eastern Pacific ocean, from the Late Miocene of Chile. Systematic Paleontology (Vertebrate Palaeontology) / Paléontologie systématique, 5: 945-952.

Bond, M. \& García, M. (2002). Nuevos restos de toxodonte (Mammalia: Notoungulata) en estratos de la Formación Chucal, Mioceno, Altiplano de Arica, norte de Chile. Revista Geológica de Chile, 29: 81-91.

Borrero L.A.; Martín, F.M. \& Prieto, A. (1997). La cueva Lago Sofía 4, Última Esperanza: una madriguera de felino del Pleistoceno tardío. Anales del Instituto de la Patagonia. Serie Ciencias Humanas, 25: 103-122.
Bown, T.H. \& Fleagle, J.G. (1993). Systematics, biostratigraphy, and dental evolution of the Palaeothentidae, Later Oligocene to Early-Middle Miocene (DeseadanSantacrucian) caenolestoid marsupials of South America. Paleontological Society, Memoir 29, Journal of Paleontology, 67: 1-76.

Brito, J.L. \& Oporto, J.A. (1990). Hallazgo de un delfínido fósil del género Globicephala en la costa central de Chile. In: Resúmenes de la $4^{a}$ Reunión de Trabajo de Especialistas en Mamíferos Acuáticos de América del Sur, 12-15 de noviembre, Valdivia, Chile.

Cabrera, A. (1926). Cetáceos fósiles del Museo de la Plata. Revista del Museo de la Plata, 29: 363-411.

Canto, J.; Yáñez, J. \& Castillo, J. (1991). Physeteridae y Pontoporiidae para el Mioceno de Chile. In: Resúmenes XVI Reunión de la Sociedad de Mamíferos Marinos de México, 2-5 de abril. 1 pp.

Canto, J. (1991). Posible presencia de Smilodon en el Pleistoceno tardío de Magallanes. Anales del Instituto de la Patagonia, Serie Ciencias Sociales, 20: 96-99.

Canto, J.; Yáñez, J.; Castillo, J. \& Sanino, G.P. (1994). Presencia de Balaenopteridae fósil en Chile. Resúmenes $6^{\text {ta }}$ Reunión de Trabajo de Especialistas en mamíferos Acuáticos de América del Sur, 24-28 de octubre, Florianapolis, Brasil.

Canto, J.; Crovetto A. \& Covacevich, V. (2002a). Hallazgo de Pliopontos sp. (Cetacea: Pontoporiidae) en el Neógeno de Chile. Noticiario Mensual Museo Nacional de Historia Natural (Chile), 350: 28-37.

Canto, J.; Yáñez J. \& Cozzuol, M. (2002b). Mamíferos marinos neógenos de la Formación Bahía Inglesa, Caldera, III Región, Chile. Primer Congreso Latinoamericano de Paleontología de Vertebrados, 29-31 de octubre, Santiago, Chile.

Canto, J. (2007). Physeteroidea (Cetacea: Odontoceti) fósiles en el Neógeno de Chile. Noticiario Mensual Museo Nacional de Historia Natural (Chile), 359: 922.

Canto, J. \& Frassinetti, D. (2008). La biodiversidad extinta en Chile. In: Biodiversidad de Chile. Patrimonio y Desafíos [Comisión Nacional del Medio Ambiente CONAMA, Segunda Edición Santiago, Chile Ed.) Ocho Libros Ediciones], 64-70.

Canto, J.; Salas-Gismondi, R.; Cozzuol M. \& Yáñez, J. (2008). The aquatic sloth Thalassocnus (Mammalia: Xenarthra) from the Late Miocene of north-central Chile: biogeographic and ecological implications. Journal of Vertebrate Paleontology, 28: 918-922. doi:10.1671/0272-4634(2008)28[918:TASTMX]2.0.CO;2

Canto J.; Yáñez, J. \& Frassinetti, D. (2009). Mamíferos Fósiles de Chile. In: Mamíferos de Chile (MuñozPedreros, A. \& Yáñez, J., Eds.), 2ª Ed., CEA Editores, Valdivia, Chile, 285-297.

Canto, J.; Fariña, R.; Yáñez, J. \& Frassinetti, D. (2009). Paleoecología y Paleoambientes de los Mamíferos Fósiles de Chile. In: Mamíferos de Chile (MuñozPedreros, A. \& Yáñez, J., eds.). 2 ${ }^{\text {a }}$ ed., CEA Editores, Valdivia, Chile, 299-304.

Casamiquela, R. (1968). Catalogación crítica de algunos vertebrados fósiles chilenos. I Los ciervos. La presen- 
cia de Antifer (= Blastocerus?) en el Pleistoceno superior. Revista Universitaria, 53: 101-106.

Casamiquela, R. \& Chong, G. (1975). Icnitas (Mammalia: Equidae?) en rocas del Plio-pleistoceno de la costa, Provincia de Antofagasta. 1. ${ }^{\text {er }}$ Congreso Argentino de Paleontología y Bioestratigrafía, 2: 621-632.

Casamiquela, R. \& Sepúlveda, F. (1974). Catalogación crítica de algunos vertebrados fósiles chilenos. III. Los megateroideos. Sobre Megatherium medinae Philippi. Ameghiniana, 11: 97-123.

Casamiquela, R. (1984). Critical catalogue of some Chilean fossil vertebrates. I. The Deers: Complementary considerations on Antifer (Antifer niemeyeri n.sp.), the Pleistocene Giant Deer. Quaternary of South America and Antarctic Peninsula, 2: 41-50.

Casamiquela, R. (1999). The Pleistocene vertebrate record of Chile. Quaternary of South America and Antartic peninsula, 7: 91-107.

Charrier, R.; Chávez, A.; Elgueta, S.; Herail, G.; Flynn, J.J.; Croft, D.A.; Wyss, A. \& García, M. (2005). Rapid tectonic and paleogeographic evolution: the Chucal anticline, altiplano of Arica, northern Chile. $5^{\text {th }}$ International Symposium of Andean Geodynamics, Université Paul Sabatier, Toulouse, France, 137-140 pp.

Charrier, R.; Pinto, L. \& Rodríguez, M.P. (2007). Tectonostatigraphic evolution of the andean orogen in Chile. In: The Geology of Chile (Moreno, T. \& Gibbons, W., eds). The Geological Society, London, 21-114.

Cione A.L. \& Tonni, E.P. (1995). Chronostratigraphy and «Land mammal-ages»: The Uquian problem. Journal of Paleontology, 69: 135-159.

Cione, A.L.; Tonni, E.P. \& Soibelzon, L. (2003). The Broken Zig-Zag: Late Cenozoic large mammal and tortoise extinction in South America. Revista del Museo Argentino de Ciencias Naturales, 5: 1-19.

Cozzuol, M. (1996). The record of aquatic mammals in southern America. Münchner Geowissenchaftliche Abhandlungen, (A) 30S: 321-342.

Croft, D.; Radic, J. \& Zurita, E. (2003a). A Miocene toxodontid (Mammalia: Notoungulata) from the sedimentary series of the Cura-Mallín Formation, Lonquimay, Chile. Revista Geológica de Chile, 30: 285-298.

Croft, D.; Bond, M.; Flynn, J.J.; Reguero M. \& Wyss, A. (2003b). Large Archaeohyracids (Typotheria: Notoungulata) from Central Chile and Patagonia, including a revision of Archaeotypotherium. Fieldiana: Geology, 49: 1-38.

Croft, D.; Flynn, J.J. \& Wyss, A. (2004). Notoungulata and Litopterna of the early Miocene Chucal fauna, northern Chile. Fieldiana: Geology, 50: 1-52.

Crof, D.; Wyss, A.; Burns, M.; Flynn, J.J. \& Grana, S. (2006). The early miocene Chucal fauna, northern Chile: new specimens and a description of its xenarthrans. Abstracts Society Vertebrate Paleontology, 26: 53A, September.

Croft, D.; Flynn, J.J. \& Wyss, A. (2007). A new basal glyptodontid and other Xenarthra of the early miocene Chucal fauna, northern Chile. Journal of Vertebrate Paleontology, 27: 781-797.

doi:10.1671/02724634(2007)27[781:ANBGAO]2.0.CO;2
Donoso-Barros, R. (1975). Contribución al conocimiento de los cetáceos vivientes y fósiles del territorio de Chile. Gayana: Zoología, 36: 1-127.

Einsenberg, J.F. (1981). The mammalian radiations: an analysis of trends in evolution, adaptation and behavior. The University of Chicago Press, $610 \mathrm{pp}$.

Flynn, J.J.; Wyss, A.; Charrier, R. \& Swisher, C.C. (1995). An Early Miocene anthropoid skull from the Chilean Andes. Nature, 373: 603-607. doi:10.1038/373603a0

Flynn, J.J. \& Wyss, A. (1998). Recent advances in South American mammalian paleontology. Trend in Ecology and Evolution, 13: 449-454. doi:10.1016/S01695347(98)01457-8

Flynn, J.J. \& Wyss, A. (1999). New marsupials from the Eocene-Oligocene transition of the Andean main range Chile. Journal of Vertebrate Paleontology, 19: 533-549.

Flynn, J.J.; Croft, D.A.; Charrier, R.; Hérail, G. \& Wyss, A. (2002a). The first Cenozoic mammal fauna from the Chilean altiplano. Journal of Vertebrate Paleontology, 22: 200-206.

doi:10.1671/0272-4634(2002)022[0200:TFCMFF]2.0.CO;2

Flynn, J.J.; Novacek, M.J.; Dodson, H.E.; Frassinetti, D.; McKenna, M.C.; Norell, M.A.; Sears, K.E.; Swisher, C.C. \& Wyss, A. (2002b). A new fossil mammal assemblage from the southern Chilean Andes: implications for geology, geochronology, and tectonics. Journal of South American Earth Sciences, 15: 285-302. doi:10.1016/S0895-9811(02)00043-3

Flynn, J.J.; Wyss, A.R.; Croft, D.A. \& Charrier, R. (2003). The Tinguiririca Fauna, Chile: biochronology, paleoecology, biogeography, and a new earliest Oligocene South American Land Mammal «Age». Palaeogeography, Palaeoclimatology, Palaeoecology, 195: 229-259. doi:10.1016/S0031-0182(03)00360-2

Flynn, J.J.; Croft, D.A.; Charrier, R.; Wyss, A.; Herail G. \& García, M. (2005). A new Mesotheriidae (Mammalia: Notoungulata: Typoteria), geochronology and tectonics of the Caragua area, northernmost Chile. Journal of South American Earth Sciences, 19: 55-74. doi:10.1016/j.jsames.2004.06.007

Fordyce, R.E. (1977). The development of the circumantartic current and the evolution of mysticeti (Mammalia: Cetacea). Paleogeographic, Paleoclimatology, Paleoecology, 21: 265-271.

Frassinetti, D. \& Azcárate, V. (1974). Presencia de Megatherium en los alrededores de Santiago (Chile). Boletín del Museo Nacional de Historia Natural (Chile), 33: 35-40.

Frassinetti, D. (1982). Bibliografía escogida y comentada sobre mamíferos fósiles de Chile. Publicación Ocasional Museo Nacional de Historia Natural (Chile), 1-24.

Frassinetti, D. (1985). Restos de mastodonte en Alto de Boroa y antecedentes de otros hallazgos en la Región de Araucanía. Boletín Museo Regional Araucanía, 2: 91-96.

Frassinetti, D. \& Salinas, P. (1986). Nuevos hallazgos de mastodontes ocurridos en Chile. Noticiario Mensual del Museo Nacional de Historia Natural (Chile), 33: 35-42.

Frassinetti, D. \& Alberdi, M.T. (2000). Revisión y estudio de los restos fósiles de mastodontes de Chile 
(Gomphotheriidae): Cuvieronus hyodon, Pleistoceno Superior. Estudios Geológicos, 56: 197-208. doi:10.3989/egeol.00563-4151

Frassinetti, D. \& Alberdi, M.T. (2001). Los macromamíferos continentales del Pleistoceno Superior de Chile: reseña histórica, localidades, restos fósiles, especies y dataciones conocidas. Estudios Geológicos, 57: 53-69. doi:10.3989/egeol.01571-2127

Frassinetti, D. \& Alberdi, M. T. (2005). Presencia del género Stegomastodon entre los restos fósiles de mastodontes de Chile (Gomphotheriidae), Pleistoceno Superior. Estudios Geológicos, 61: 101-107. doi:10.3989/egeol.05611-245

Gaskin, D. E. (1985).The ecology of whales and dolphins. Heineman London, 459 pp.

Gay, C. (1847). Historia física y política de Chile. Zoología, 1 Mamíferos, 182 pp.

Gigoux, E. (1899). Un fósil más en Caldera. Revista Chilena de Historia Natural, 3: 129-131.

Gigoux, E. (1913). Terrenos y fósiles de Caldera. Actes Societé Scientifique du Chili, 23: 47-56.

Gould, S.J. (1983). Nature's great era of experiments. Natural History, 7: 17-21.

Gradstein, D. \& Ogg, C. (2004).Geological Time Scale 2004-Why, how and where next. http://www.stratigraphy.org/scale04.pdf.

Hampe, O. (2006). Middle/late Miocene hoplocetine sperm whale remains (Odontoceti: Physeteridae) of North Germany with an emended classification of the Hoplocetinae. Fosil Record, 9: 61-68. doi:10.1002/mmng.200600002

Hinojosa, F. \& Villagrán, C. (1997). Historia de los bosques del sur de Sudamérica, I: antecedentes paleobotanicos, geológicos y climáticos del Terciario del cono sur de América. Revista Chilena de Historia Natural, 70: 225-239.

Hitz, R.B.; Flynn, J.J. \& Wyss, A. (2006). New basal Interatheriidae (Typotheria: Notoungulata: Mammalia) from the Paleogene of Central Chile. American Museum Novitates, 3520: 1-32. doi:10.1206/00030082(2006)3520[1:NBITNM]2.0.CO;2

Kardong, K. (1999). Vertebrados: anatomía comparada, función, evolución. McGraw Hill - Interamericana, Segunda Edición, 732 pp.

Latorre, C. (1998). Paleontología de mamíferos del Alero Tres Arroyos I, Tierra del Fuego, XII Región, Chile. Anales del Instituto de la Patagonia, Serie Ciencias Naturales, 26: 77-90.

Lessa, E.P. \& Fariña, R. (1996). Reassessment of the extintion patters among the late Pleistocene mammals of South America. Paleontology, 39: 651-662.

Labarca, R.O. \& López, P. (2006). Los mamíferos finipleistocénicos de la Formación Quebrada Quereo (IV Región-Chile): biogeografía, bioestratigrafía e inferencias paleoambientales. Mastozoología neotropical, 13: 89-101.

López, P.; Martínez, I.; Labarca, R. \& Jackson, D. (2005). Registro de Hippidion, Canidae, Camelidae y Edentata en el sector Ojo Opache, Calama II Región. Noticiario Mensual del Museo Nacional de Historia Natural, 356: 22-26.
López, P. (2007). Tafonomía de los mamíferos extintos del Pleistoceno tardío de la costa meridional del semiárido de chile (IV Región-32 ${ }^{\circ}$ latitud S), alcances culturales y paleoecológicos. Chungara, Revista de Antropología Chilena, 39: 86-69.

Lou, Z.; Kielan Jaworowska, Z. \& Cifelli, R. (2002). In quest for a phylogeny of mesozoic mamals. Acta Paleontologica Polonica, 47: 1-78.

Marquardt, C.; Blanco, N.; Godoy, E.; Lavenu, A.; Ortlieb, L.; Marchant, M. y Guzmán, N. (2000). Estratigrafía del Cenozoico superior en el área de Caldera $\left(26^{\circ} 45^{\prime}-28^{\circ} \mathrm{S}\right)$. Actas IX Congreso Geológico Chileno, V2, 588-592.

Marshall, L.G. (1982). Mammalian evolution and the great american interchange. Science, 215: 1351-1357. doi:10.1126/science.215.4538.1351

Marshall, L.G. (1990). Fossil marsupials from the type Friasian land mammal age (Miocene), Alto Río Cisnes, Aisén, Chile. Revista Geológica de Chile, 17: 19-55.

Marshall, L.G.; Hoffstetter, R. \& Pascual, R. (1983). Mammals and stratigraphy: geochronology of the continental mammal-bearing Tertiary of South America. Palaeovertebrata, Memoire Extraordinaire, 1983: 1-93.

Marshall, L.G. \& Salinas, P. (1989-1990). Vertebrados continentales del Mioceno temprano de Magallanes, sur de Chile. Anales del Instituto de la Patagonia, 19: 27-38.

Martínez, R. (1990). Major Neogene events of the Southeastern Pacific: the Chilean and Peruvian record. Palaeogeography, Palaeoclimatology, Palaeoecology, 77: 263-278. doi:10.1016/0031-0182(90)90180-F

Mazo, A.V. (1995). Proboscídeos. En: Paleontología: Mamíferos [3 (2) Meléndez, B., ed.], Editorial Paraninfo, Madrid, 251-309.

McKenna, M.C. \& Bell, S. (1997). Classification of mammals. Above the species level. Columbia University Press, New York, 631 pp.

McKenna, M.; Wyss, A. \& Flynn, J.J. (2006). Paleogene Pseudoglyptodont Xenarthrans from Central Chile and Argentine Patagonia. American Museum Novitates, 3536: $1-18$. doi:10.1206/0003-0082(2006)3536[1:PPXFCC]2.0.CO;2

Meléndez, B. (1990). Desdentados. In: Paleontología 3: Mamíferos, 1a parte (Meléndez, B, Ed.), Editorial Paraninfo, Madrid, 173-212.

Meléndez, B. (1995). Mutica (Cetáceos). In: Paleontología 3: Mamíferos, 2ª parte (Meléndez, B., Ed.). Editorial Paraninfo, Madrid, 1-26.

Mol, D.; Van Bree, P.J.H. \& Mcdonald, G. (2003). De Amsterdame collectie fossielen uit de Grot van Última Esperanza, Patagonië, Zuid-Chili. Grondboor \& Hamer, 2: 26-36.

Morales, J. \& Soria, D. (1990). Credontos y carnívoros. In: Paleontología 3: Mamíferos, 2a parte (Meléndez, B., Ed.). Editorial Paraninfo, Madrid, 313-354.

Moreno, P.; Marshall, L.G. \& Salinas, P. (1991). Mamíferos pleistocénicos del norte y centro de Chile en su contexto geográfico. Resúmenes expandidos $6^{\circ}$ Congreso Geológico Chileno, 670-673.

Moreno, P.; Villagrán, C.; Marquet, P. y Marshall, L.G. (1994). Quaternary paleobiogeography of northern and 
central Chile. Revista Chilena de Historia Natural, 67: 487-502.

Muizon, C. de (1988). Les vetérbrés fossiles de la Formation Pisco (Pérou), Troisieme partie: Les odontocetes (Cetacea:Mammalia) du Miocene. Editions Recherche sur les Civilisations. Memorie, 78: 1-239.

Muñoz-Pedreros, A. \& Yáñez, C. (2000). Mamíferos de Chile. CEA Editores, Valdivia, Chile, $462 \mathrm{pp}$.

Nami, H. (1987). Cueva del medio: perspectivas arqueológicas para la Patagonia austral. Anales del Instituto de la Patagonia, Serie Ciencias Humanas, 17: 73-106.

Nami, H. \& Menegaz, A. (1991). Cueva del medio: aportes para el conocimiento de la diversidad faunística hacia el Pleistoceno-Holoceno en la Patagonia austral. Anales del Instituto de la Patagonia, 20: 117-132.

Núñez, L.; Varela, J.; Casamiquela, R.; Shiappacasse, V.; Niemeyer, H. \& Villagrán, C. (1994). Cuenca de Taguatagua en Chile, Pleistoceno superior y ocupaciones humanas. Revista Chilena de Historia Natural, 67: 503-519.

Oliver-Schneider, C. (1926). Lista preliminar de los mamíferos marinos fósiles de Chile. Revista Chilena de Historia Natural, 30: 144-156.

Oliver-Schneider, C. (1935). Mamíferos fósiles de Chile (Adiciones y correcciones a la lista preliminar). Revista Chilena de Historia Natural, 39: 297-304.

Ortiz-Jaureguizar, E. \& Cladera, G.A. (2006). Paleoenviromental evolution of southern South America during the Cenozoic. Journal of arid enviromentals, 66: 498-532

Pascual, R.; Ortiz-Jaureguizar, E. \& Prado, J.L. (1996). Land: paradigm for cenozoic South America geobiotic evolution. Müchner Geowissenschaftliche Abhandlungen, A 30: 265-319.

Pascual, R. \& Ortiz-Jaureguizar, E. (2007). The Gondwanan and South American episodes: two major and unrelated moments in the history of the South American Mammals. Journal of Mammalogy Evolution, 14: 75-137. doi:10.1007/s109140079039-5

Paula Couto, C. de (1979). Tratado de Paleomastozoología. Academia Brasileira de Ciencias, 590 pp.

Philippi, R.A. (1887). Los fósiles terciarios i cuartarios de Chile. Imprenta Brokhaus, Leipzing, $256 \mathrm{pp}$.

Prado, J.L. \& Alberdi, M.T. (1994). A quantitative review of the horse Equus from South American. Paleontology, 37: 459-481.

Prevosti, F.; Soibelzon, L.H.; Prieto, A.; San Román, M. \& Morello, F. (2003). The southernmost bear Pararctotherium (Carnivora: Ursidae: Tremartinae) in the latest Pleistocene of Southern Patagonia, Chile. Journal of Vertebrate Paleontology, 23: 709-712. doi:10.1671/0272-4634(2003)023[0709:TSBPCU]2.0.CO;2

Prieto, A. \& Canto, J. (1997). Presencia de un Lamoíde atípico en Cueva Lago Sofía 4 (Última Esperanza) y Tres Arroyos (Tierra del Fuego) Región de Magallanes, Chile. Anales del Instituto de la Patagonia, Serie Ciencias Humanas, 25: 147-150.

Reig, O. (1981). Teoría del origen y desarrollo de la fauna de mamíferos de América del Sur. Monographiae Naturae. Museo Municipal de Ciencias Naturales Lorenzo Scaglia, Mar del Plata, Argentina, 159 pp.
Redford, K.H. \& Einsenberg, J.F. (1992). Mammals of neotropics, the southern cone. (2) University of Chicago Press, $430 \mathrm{pp}$.

Reguero, M.A.; Croft, D.A.; Flynn, J.J. \& Wyss, A.R. (2003). Small Archaeochyracids (Typotheria: Notoungulata) and Central Chile: implications for trans-Andean temporal correlation. Fieldiana: Geology, 48: 1-17.

Reyes, J.C. \& Molina, D.M. (1997). Clave artificial para la identificación de cráneos de cetáceos del Pacífico Sureste. Boletin Museo Nacional de Historia Natural (Chile), 46: 95-119.

Roth, S. (1899). El mamífero misterioso de la Patagonia Grypotherium domesticum. Descripción de los restos encontrados en la caverna de Última Esperanza. Revista Museo de La Plata, 9: 13-45.

Salinas, P. (1988). Hallazgo de cetáceos fósiles (Mysticeti: Balaenopteridae) en la ciudad de Coquimbo. Revista Geológica de Chile, 15: 89-94.

San Román, M.; Morello, F. \& Prieto, A. (2000). Cueva de los Chingues (Parque Nacional Pali Aike), Magallanes, Chile. Historia Natural y Cultural I. Anales del Instituto de la Patagonia, Serie Ciencias Humanas, 28: 125-146.

Sielfeld, W.K. (1983). Mamíferos Marinos de Chile. Ed. Universidad de Chile. 199 pp.

Simpson, G.G. (1941). A Miocene sloth from southern Chile. American Museum Novitates, 1156: 1-6.

Simpson, G.G. (1985). Fósiles e Historia de la Vida. Biblioteca Scientific American. Prensa Científica Editorial Labor, 240 pp.

Smith Woodward, A. (1900). On some remains of Grypotherium (Neomylodon) listai and associated mammals from cavern near Consuelo cove, last hope inlet, Patagonia. Proceedings of the Zoological Society of London, 1: 64-75.

doi: 10.1111/j.1096-3642.1890.tb01704.x

Soibelzon, L.H. (2004). Revisión sistemática de los Tremarctinae (Carnivora: Ursidae) fósiles de América del Sur. Revista Museo Argentino de Ciencias Naturales, 6: 107-133.

Soria, D. (1990). Marsupiales. In: Paleontología 3: Mamíferos, $1^{\mathrm{a}}$ parte (Meléndez, B., Ed.). Editorial Paraninfo, Madrid, 109-172.

Staig, F.; Canto, J. \& Hillebrandt, S. (2004). Primer Salvataje de cetáceo (Mysticeti) fósil de la Formación Coquimbo, IV Región, Chile. In: XXIV Congresos de Ciencias del Mar. Universidad Católica del Norte, 17-20 mayo, $182 \mathrm{pp}$.

Tamayo, M. \& Frassinetti, D. (1980). Catálogo de los mamíferos fósiles y vivientes de Chile. Boletín Museo Nacional Historia Natural (Chile), 37: 323-399.

Uhen, M.D. \& Pyenson, N.D. (2007). Diversity estimates, biases, and historiographic effects: resolving cetacean diversity in the Tertiary. Paleontología Electrónica. 10 (2) http://palaeo-electronica.org/2007_2/00123/index.html.

Velásquez, H. \& Mena, F. (2006). Distribuciones óseas de ungulados en la cueva Baño Nuevo-1 (XI Región, Chile): un primer acercamiento. Magallania, 34: 91-106.

Walsh, S.A. \& Naish, D. (2002). Fossil seals from Late Neogene deposit in South America: a new pinniped 
(Carnivora, Mammalia) assemblage from Chile. $\mathrm{Pa}$ leontology, 45: 821-842. doi:10.1111/1475-4983.00262

Webb, S.D. (1976). Mammalian faunal dynamics of the Great American interchange. Paleobiology, 2: 216-234.

Webb, S.D. (2006). The Great American biotic interchange: patterns and processes. Annals of the Missouri Botanical Garden, 93: 245-257. doi:10.3417/00266493(2006)93[245:TGABIP]2.0.CO;2

Wyss, A.; Flynn, J.J.; Norell, M.A.; Swisher, S.S.; Novaceck, M.J.; McKenna, M.C. \& Charrier, R. (1994). Paleogene mamals from the Andes of central Chile: a preliminary taxonomic biostratigraphic and geocronologic assessment. American Museum Novitates, 3098: 1-31.
Wyman, J. (1855). Description of a portion of the lower jaw and the tooth of Mastodon andium; also, of a tooth and fragment of the fémur of a Mastodon from Chile. U.S.N.Ast.Exp.to the South Hemisphere, 2: 275-281.

Yáñez, J. \& Canto, J. (1991). Rectificación de la determinación de cetáceos fósiles de Coquimbo, Chile. Revista Geológica de Chile, 18: 181-182.

Yáñez, J.; Canto, J. \& Reyes, J. (1994). Cráneo fósil de Phocoena spinipinnis (Cetacea: Phocoenidae). Noticiario Mensual Museo Nacional de Historia Natural (Chile), 324: 25-29.

Recibido el 26 de noviembre de 2008

Aceptado el 19 de mayo de 2009 Publicado online el 3 de noviembre de 2009 